\title{
Cosmetics in use: a pharmacological review
}

\section{Abstract}

"Cosmetics" really comes from its utilization in Ancient Rome. They were commonly delivered by female slaves known as "cosmetae," which is the place "cosmetics" originated from. Cosmetics are utilized to upgrade appearance. Makeup has been around for a long time. The primary known individuals who utilized cosmetics to upgrade their beauty were the Egyptians. Makeup those days was simply basic eye shading or some material for the body. Presently a-days makeup assumes an imperative job for the two men and women. In developmental brain science, social challenge of appearance reinforces women's wants for perfect beauty. As indicated by "The Origin of Species", people have developed to exchange qualities to future ages through sexual determination that respects the body state of perfect beauty as astounding richness. Also, since women's beauty has as of late been viewed as an upper hand to make social power, a body that satisfies the social guidelines of a culture could accomplish restricted social assets. It's hard to believe, but it's true, even men have turned out to be more beauty cognizant and are worried about their looks. Cosmetics can be delivered in the natural and hypoallergenic structure to fulfill the needs of clients. Makeup is utilized as a beauty help to help develop the self-esteem and certainty of a person. The significance of cosmetics has expanded the same number of individuals need to remain youthful and alluring. Cosmetics are promptly accessible today as creams, lipstick, scents, eye shadows, nail shines, hair showers and so forth. Different cosmetics like face powder offer gleam to the skin subsequent to applying the base cream. At that point we have lipsticks, which are connected by numerous women all things considered. They are produced using wax and cocoa butter in the ideal sum. Cosmetics like creams, gels, and colognes are utilized consistently by the two women and men. Creams go about as a chemical for the face as a rule. All the more as of late enemy of maturing creams have been made which can hold more youthful looking skin for a long time. The best cleansing specialists are cleansing cream, cleanser and water. Cosmetic creams fill in as skin sustenance for hard, dry and dry skin. It fundamentally greases up, diminishes and expels undesirable earth from the skin. Some famous fat creams that are utilized incorporate Vaseline and Lanolin. Dry creams are utilized in the assembling of cleanser and gelatin which is utilized as a base for the skin. Hair care has turned out to be one of the quickest creating markets in the beauty business. Numerous young fellows swing to oils and gels to keep up and style their hair. Items like hair gels, oils, and moisturizers have been acquainted in the market with assistance ensure hair fall and dandruff. A few callings, similar to the entertainment biz industry, center on the significance of the external appearance. Numerous identities and craftsmen have used makeup to beat the brutal lights and the glare of camera flashes. They know the significance of their looks and keep up them by utilizing an assortment of cosmetics. Their appearance is their most profitable resource and they accept each undertaking to show up as the fans need them to show up. Late research has demonstrated that makeup helps in assurance from destructive beams of the sun. Numerous beauty items producers have used the necessities of individuals to shield
Volume 3 Issue 2 - 2019

\author{
Mohiuddin AK \\ Department of Pharmacy, World University of Bangladesh \\ Bangladesh
}

Correspondence: Mohiuddin AK, Assistant Professor, Department of Pharmacy, World University of Bangladesh, |5 |/8, Green Road, Dhanmondi, Dhaka-1205, Bangladesh, Te| +8801716477485, Email mohiuddin3@pharmacy.wub.edu.bd

Received: April 16, 2019 | Published: April 30, 2019

themselves and their skin from the beams of the sun. This is an extraordinary achievement on the grounds that prior make up and sun assurance could not mix together. Today Cosmetics help to upgrade our appearance and make us feel increasingly certain. With more cosmetics available today than any other time in recent memory, it ends up clear to us that they assume an extraordinary job in our regular daily existence (Figure 1).

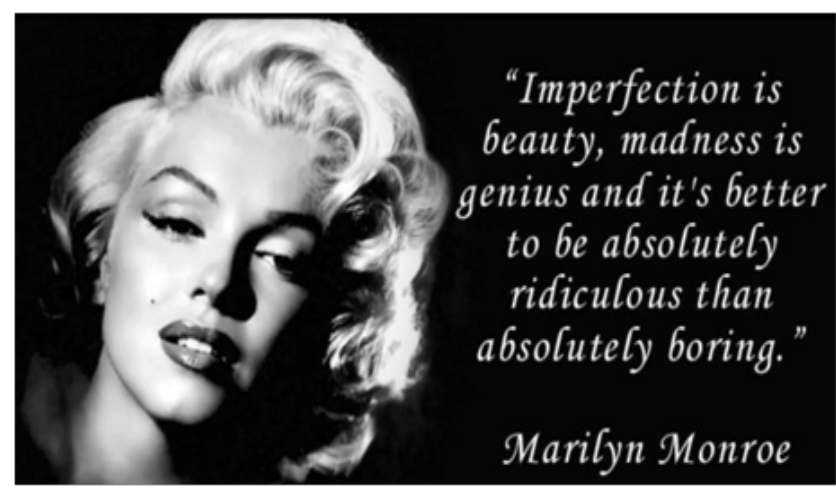

Figure I Famous Beauty Quote, Merlyn Monroe . ${ }^{1-5}$ The "blonde bombshell" had a heavy peach fuzz "beard" but refused to wax it off. But her so called "imperfection" never left without cosmetics. Monroe used five different lipsticks and glosses to create her pouty look. Between shampoo jobs, she was said to have applied baby powder on the roots of her hair. To get skin glow, Monroe slathered on thick layers of Vaseline or Nivea Cream under her makeup before getting in front of the camera. She was also a huge fan of moisturizers, olive oil, and lanolin. She wasn't always a blonde bombshell—she was born a brunette. She dyed her hair golden blonde when a modeling agency told her it would make her more successful.

body' (this incorporates the mouth and teeth). We use cosmetics to wash down, fragrance, secure and change the presence of our bodies or to modify its smells. Items that guarantee to 'change a substantial procedure or forestall, analyze, fix or ease any malady, ailment or deformity' are called therapeutics. Most cosmetic items are mind boggling blends of substance aggravates that are straightforwardly connected to the skin. In contrast to pharmaceutical items, cosmetics are not planned to fix maladies. Be that as it may, present day cosmetics are regularly "functional." Products for brightening wrinkle care, saturating, and treating pores, spots, and so on are delivered to address the issues of the present consumers. Subsequently, some cosmetic items contain semi drugs, in spite of the fact that their consequences for the body stay mellow and delicate.

A cosmetic item is characterized as 'A substance or readiness planned for placement in contact with any outer piece of the human 
Since cosmetics are uninhibitedly utilized by consumers with no every day introduction restricts, the retention of semi drugs (and different fixings) through the skin should be deliberately controlled, which makes checking transdermal medication ingestion one of the imperative subjects in cosmetic science. In spite of the fact that utilization and acknowledgment of the expression 'cosmeceutical' may generally be bound to the U.S., knowledgeable and progressively requesting consumers have no national outskirts-and the onus to satisfy these requests is on both brand proprietors and fixing providers. As per investigate firm Kline and Company's "Claim to fame Actives in Personal Care 2011: U.S. Market Analysis and Opportunities," a developing shopper comprehension of dynamic fixings in close to home consideration items, driven by broad purchaser media inclusion, is compelling providers of dynamic fixings to deliver inventive items ("imaginative" and "dynamic" are the signs of cosmeceuticals). When searching out close to home consideration, consumers need the new and energizing, while their desires for and of functional and effectual fixings and items develop. Furthermore, because of worldwide financial matters, purchaser cheapness has turned into the new ordinary, and this, as well, assumes a job in what consumers anticipate from the execution of their items. Consumers will keep on spending on beauty items, yet as their spending power diminishes, they are ever snappier to proceed onward from an item they consider as not satisfying its guarantees. Consumers set the parameters and will keep on searching out the best beauty items for their necessities and esteem is resolved first on viability. On its essence, achieving the present consumers and winning their purchase for the long haul appears an always overwhelming suggestion, however their journey and strive after perpetually solid and captivating items really makes an interpretation of two more chances to develop for new neglected necessities. Transforming development into progress, however, will genuinely rely upon a transparent discussion with consumers-tuning in to their requirements and being as clear as conceivable about cases and the potential for some random item. Brand proprietors must pass on the estimation of new fixings, recipes and items through clear language, with clarifications of advantages dependent on logical examinations or different preliminaries. Sponsorship great fixings and items by creating brilliant showcasing efforts that can pass on proper desires from the utilization of items will encourage a huge association with consumers-and that means the development of business (Figure 2).

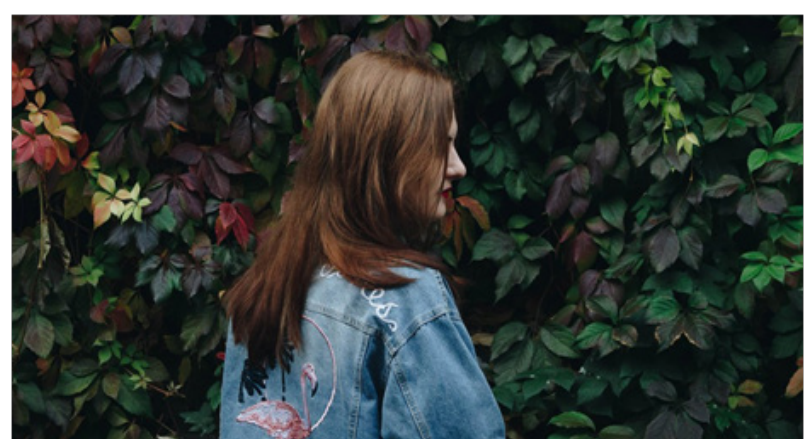

Figure 2 How Do Plant Stem Cells Help Hair Growth?,7 Plant stem cells possess similar genetic factors as human stem cells and can be used to influence the function of certain cells in our skin and hair follicles. Active plant stem cells work to increase the lifespan of hair follicles so that hair can remain in the anagen phase of the hair growth cycle for a longer period of time. Another hair-growth benefit of Asparagus Stem Cells is their ability to block the most common hair-killing hormone, DHT. High levels of DHT, as well as sensitivity to the hormone, are known for causing most male-pattern baldness and even female alopecia. Asparagus Stem Cells can aid the receptors in the skin to block the intrusion of DHT, and therefore minimizing the hair loss

caused by it.

\section{History of skin care}

In spite of the fact that cosmetics have likely existed for significantly more, the principal proof of cosmetics comes from Ancient Egypt, around 6,000years prior. They utilized cosmetics for an assortment of reasons, the first being for embalmment, entombment conventions, and regarding their Gods and Goddesses. They additionally utilized cosmetics to shield them from the components-chiefly sun beams and bugs. Egyptians-like utilizing aloe, myrrh, and frankincense. These items, especially frankincense, were accepted to have mitigating properties and were utilized as hostile to wrinkle creams by Ancient Egyptians. Cosmetics was made utilizing an assortment of items including metal mineral, copper, water, oil, creature fat, and valuable stones. While Ancient Greeks and Romans utilized the thoughts of the Ancient Egyptians, they took their skincare and magnificence ceremonies above and beyond. Numerous Greeks and Romans would spend a whole day at the "spa" to concentrate on their skin. Ladies usually utilized white lead, crocodile excrement, and chalk so as to help the presence of their skin. They likewise made face covers with starch and eggs, which were accepted to fix the skin, diminish wrinkles, and keep the face looking as energetic as would be prudent. This was significantly progressively normal in China, especially under the Shang Dynasty (in 1760BC). A powdered face with smooth skin was very mainstream and white powders were utilized to accomplish the whitest composition conceivable. Making it another stride further, numerous additionally utilized gels and salves to for all time blanch their skin. As skincare moved to Europe and the Middle East, new fixings and techniques were concocted and presented. The primary virus cream was created utilizing rose oil and water, and liquefying beeswax into it. They utilized the mineral alum to treat scabs and utilized olive lead to battle skin inflammation. They joined vinegar and lead to make a brightening establishment and utilized it to dispose of spots and brighten their skin. Amid the Elizabethan Era, numerous Europeans utilized this brightening establishment. At the time, it wasn't mainstream to wash their countenances and additionally bodies, so commonly, they heaped on layer after layer of the brightening establishment to accomplish a look as pale as could be expected under the circumstances. In spite of the numerous social steps made in the late 1800 's and mid 1900's, dark skin was as yet observed as unfortunate. Skin brightening was as prominent as ever and items were made almost only for light skinned ladies. By the 1920 's, a move in magnificence goals made marginally tanned skin is viewed as attractive. Cosmetics, thusly, pursued this pattern. Tinted face powders and moisturizers that copied a tan were presented.

\section{General use of cosmetics}

Cosmetic is a Greek word which intends to 'adorn' (expansion of something ornamental to an individual or a thing). It might be characterized as a substance which interacts with different pieces of the human body like skin, hair, nail, lips, teeth, and mucous layers and so forth. Cosmetic substances help in improving or changing the outward show of the body and furthermore veil the smell of the body. It secures the skin and keeps it in great condition. All in all, cosmetics are outer arrangements which are connected on the outside parts the body. Indeed, even in prior days, men and women used to embellish their bodies for improvement of appearance. Men utilized leaves of vegetables and parts of creatures while women use to wear hued stones and blooms round their neck and wrist. Step by step, they begin utilizing shaded earth and ointments all over and body. Indeed, even bangles and neckband made of prepared earth materials turned out to be exceptionally regular among the general population. Eye shadow were made of copper (hued earth) metal and light dark (hued earth) while red shading was utilized for coloring of hair. Presently 
days, cosmetics are considered as fundamental segments throughout everyday life. They pull in the general population towards it yet in addition give mental impacts. It has picked up prevalence in the last 3-4 decades and its utilization has been expanded exponentially both in males and females. The most famous cosmetics are hair colors, powders and creams.

i. Foundation used to smooth out the face and cover spots or uneven skin coloration. Usually a liquid, cream, or powder.

ii. Powder, used to set the foundation, giving a matte finish, and also to conceal small flaws or blemishes.

iii. Rouge, blush or blusher, cheek coloring used to bring out the color in the cheeks and make the cheekbones appear more defined. This comes in powder, cream, and liquid forms.

iv. Bronzer, used to give skin a bit of color by adding a golden or bronze glow.

v. Mascara is used to darken, lengthen, and thicken the eyelashes. It is available in natural colors such as brown and black, but also comes in bolder colors such as blue, pink, or purple. There are many different formulas, including waterproof for those of us prone to allergies or sudden tears.

vi. Eye liner, eye shadow, eye shimmer, and glitter eye pencils as well as different color pencils used to color and emphasize the eyelids (larger eyes give a more youthful appearance).

vii. Eyebrow pencils, creams, waxes, gels and powders are used to color and define the brows.

viii. Nail polish, used to color the fingernails and toenails.

ix. Concealer, Makeup used to cover any imperfections of the skin.

Also included in the general category of cosmetics are skin care products. These include creams and lotions to moisturize the face and body, sunscreens to protect the skin from damaging UV radiation, and treatment products to repair or hide skin imperfections (acne, wrinkles, dark circles under eyes, etc.). Cosmetics can also be described by the form of the product, as well as the area for application. Cosmetics can be liquid, cream emulsions, powders; both pressed and loose; dispersions; and anhydrous creams or sticks. ${ }^{7-11}$

\section{Exhibit I Interesting facts from history of cosmetics ${ }^{12-17}$}

Women are susceptible to the societal pressures of using cosmetics to beautify themselves. One theory behind the origins of the $q$ symbol used to denote "woman" is that it represents the hand mirror used by the Roman goddess Venus or the Greek goddess Aphrodite. In their endeavors to look wonderful, men and women apply cosmetics to conceal their blemishes and complement their highlights. Cosmetics have been a piece of mankind's history as far back as the old Egyptians. The antiquated Egyptians, Romans, and Greeks utilized different fixings to mollify, improve, peel, and detoxify skin. The antiquated Romans and Greeks utilized walnut separates as hair color, antimony (a known lethal overwhelming metal) as eye shadow, white lead carbonate as a skin lightener, charcoal crocodile excrement as a skin darkener, and cinnabar as rouge. Atropa Belladona is a toxic plant called fatal nightshade. The name belladonna originates from the Italian, which means delightful woman, starting either from its utilization as a facial cosmetic, or, all the more presumably, from its utilization to expand understudy measure in women on the grounds that amid the Renaissance the herb was utilized in eye-drops by women to widen the students of the eyes to influence them to seem enchanting. In Elizabethan England, colored red hair becomes stylish. Society women wear egg whites over their countenances to make the presence of a paler appearance. Women in Ancient Egypt utilized kohl, a substance containing powdered galena (lead sulfide- $\mathrm{PbS}$ ) to darken their eyelids, and Cleopatra is said to have washed in milk to brighten and diminish her skin. By 3000 B.C men and women in China had started to recolor their fingernails with hues as indicated by their social class. The Chinese re-colored their fingernails with gum arabic, gelatin, beeswax, and egg. Chou administration royals don gold and silver, with ensuing royals sporting dark or red. Lower classes were prohibited to wear splendid hues on their nails. Greek women utilized harmful lead carbonate $\left(\mathrm{PbCO}_{3}\right)$ to accomplish a pale composition. Muds were ground into glues for cosmetic use in conventional African social orders and indigenous Australians still utilize a wide scope of pounded rocks and minerals to make body paint for services and commencements (Figure 3).

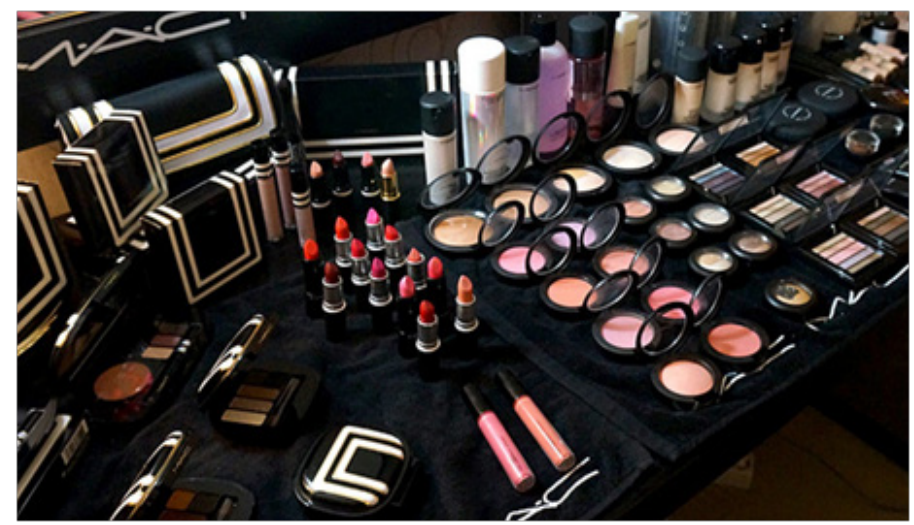

Figure 3 Modern Day Cosmetics. ${ }^{18,19}$ Professional makeup artists have been perfecting techniques to get ordinary beauty products to multi-task for years. Cosmetics companies are now using advanced technology to develop multipurpose products that emulate these techniques. Foundations are no longer designed to simply smooth complexions. Many now boast different ingredients to target varying skin needs, such as salicylic acid for acne or jojoba oil for dry skin. Numerous brands have also created multipurpose stains with a creamy consistency and a neutral color that can be used on cheeks, lips and eyes. Some shades of these creamy all-over-color sticks also offer a little shimmer or gold sparkle, so that it can glide across eyebrow bones, shoulders or cleavage as a highlighter -- Lauren Balukonis, beauty division at 5W Public Relations.

\section{Products classified as cosmetics}

Skin Creams is considered pharmaceutical products as even cosmetic creams are based on techniques developed by pharmacy and unmedicated creams are highly used in a variety of skin conditions in ancient times, creams were simply prepared by mixing of two or more ingredients using water as the solvent. With the advancement in innovation, more up to date techniques are utilized for definition of creams. These semisolid arrangements are rich to use by people in general and society. They show flexibility in their capacities. Creams can be connected to any piece of the body effortlessly. It is advantageous to utilize cream by all the age gathering of individuals. In spite of the fact that it might be similarly all around connected to non-watery items, for example, wax-dissolvable based mascaras, fluid eye shadows and ointments. On the off chance that an emulsion is adequately low consistency to be pourable (stream under impact of gravity alone) is alluded to as salve. Creams are emulsions of oil and water. In coming future, further developed advancements and strategies will be utilized for readiness, detailing and assessment of creams. Additionally, the interest of herbal constituents-based creams is expanding step by step (Figure 4). ${ }^{20-25}$ 


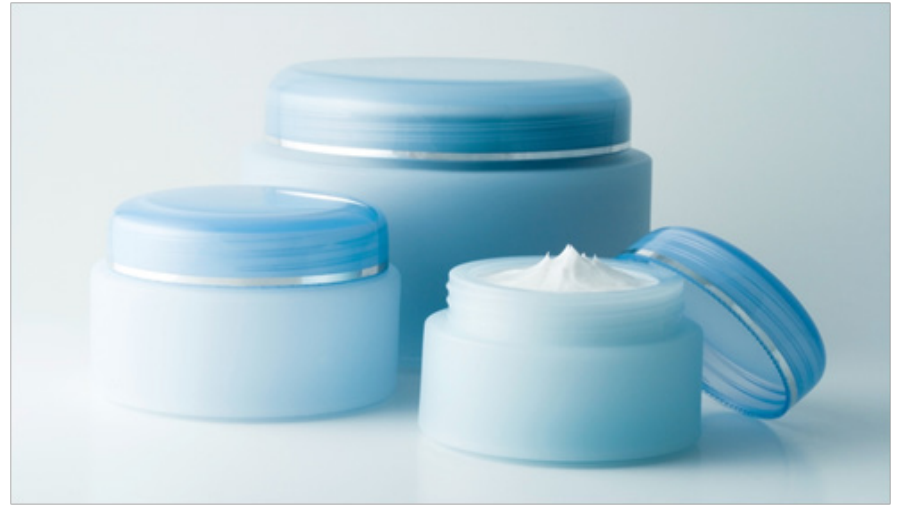

Figure 4 Skin Creams. ${ }^{26}$ In general, creams for the skin should protect it from the sun and environmental pollutants, while also treating any specific problems. Look for the highest quality ingredients to ensure a cream's ability to live up to its claims. Enhance the circulation of blood flow by massaging creams into your skin several times a day.

Lips makeup: Lipstick, lip gloss, lip liner, lip plumper, lip balm, lip stain, lip conditioner, lip primer, lip boosters, and lip butters. Lipsticks are intended to add color and texture to the lips and often come in a wide range of colors, as well as finishes such as matte, satin, gloss and luster. Lip stains have a water or gel base and may contain alcohol to help the product stay on leaving a matte look. They temporarily saturate the lips with a dye. Usually designed to be waterproof, the product may come with an applicator brush, directly through the applicator, rollerball, or could be applied with a finger. Lip glosses are intended to add shine to the lips and may add a tint of color, as well as being scented or flavored for a pop of fun. Lip balms are most often used to moisturize, tint, and protect the lips. Some brands contain sunscreen. Using a priming lip product such as lip balm or chapstick can prevent chapped lips (Figure 5). ${ }^{27-30}$

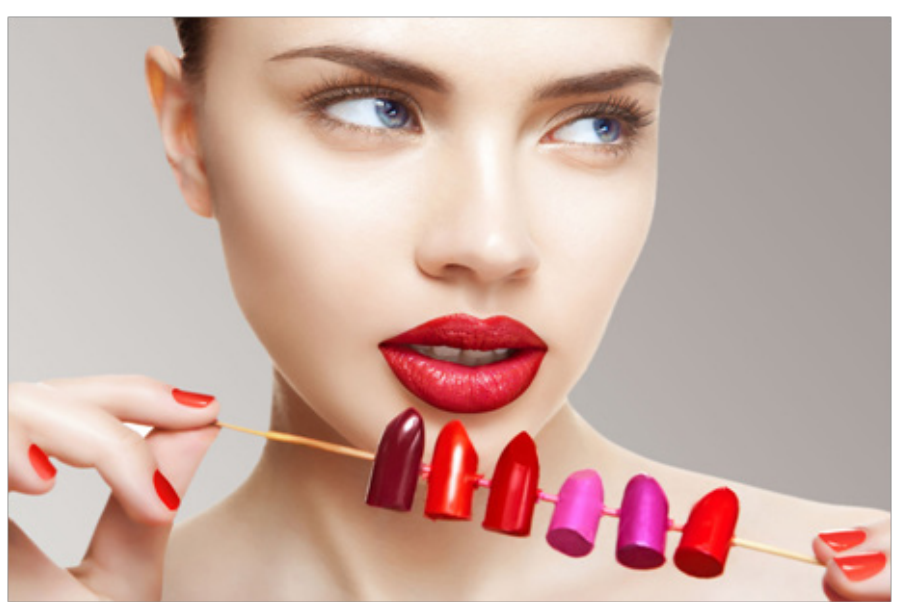

Figure 5 Lip Color. ${ }^{31-33}$ Makeup artists and advertisements for cosmetics often claim that lip color can influence facial skin's apparent lightness. Currently, we do not have scientific evidence to either support or deny these claims. The luminance contrast between facial features and facial skin is greater in women than in men, and women's use of make-up enhances this contrast. In blackand-white photographs, increased luminance contrast enhances femininity and attractiveness in women's faces, but reduces masculinity and attractiveness in men's faces. In Caucasians, much of the contrast between the lips and facial skin is in redness. Red lips have been considered attractive in women in geographically and temporally diverse cultures, possibly because they mimic vasodilatation associated with eternal desire.
Primers: Primers are so beloved by experts because they can do so much more than just make foundation go on smoother. Primers are sort of like insurance for makeup. Despite the fact that they regularly wear numerous caps - smoothing, disguising, securing and preparingtheir primary jobs are to keep makeup on longer and give skin a smooth, faultless completion. This makes another layer between skin to anticipate skin break out and makeup stopping up pores. Preliminary makes an even tone all through the skin and makes makeup last more. Groundwork is connected all through the face including eyes, lips, and lashes. This item has a velvety surface and applies easily. Numerous makeup preliminaries are planned with silicone-based polymers, as dimethicone, in light of their ultra-smoothing impacts. Photoaged skin results from different environmental variables, in particular constant sun presentation. Dyschromia and scarcely discernible differences/ wrinkles are normal clinical appearances of photodamaged skin. The facial preliminary was appeared to be compelling and all around endured for quick and long haul improvement in the presence of mellow to direct hyper pigmentation and barely recognizable differences related with photo damage when utilized over a 12-week time frame (Figure 6). ${ }^{34-37}$

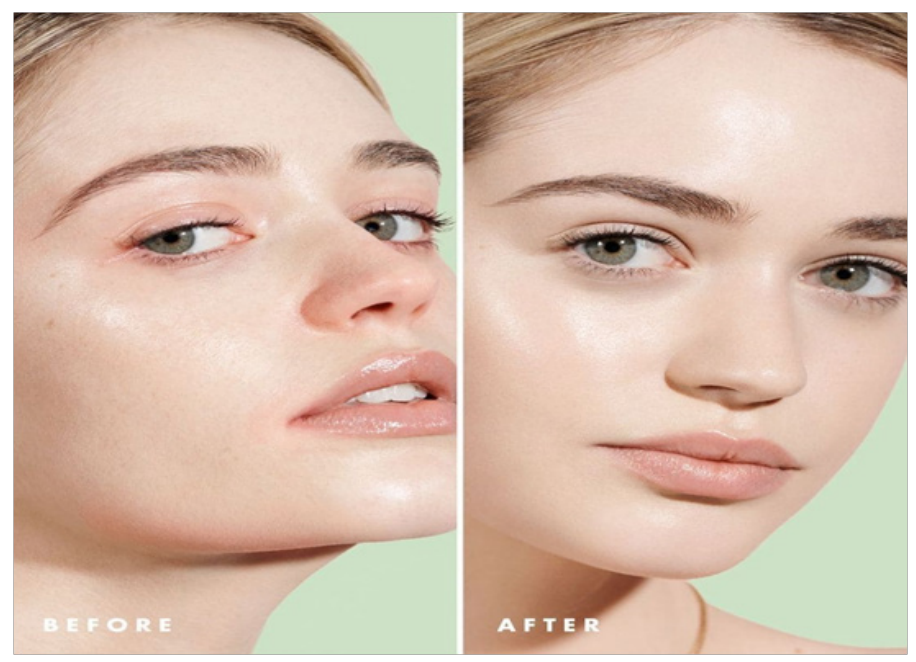

Figure 6 Comparison Between Before and After Use of Mineral Primer. ${ }^{36,38}$ Photoaged skin is largely a result of chronic exposure to UV radiation. Photo aging, which causes premature aging in the appearance and function of the skin, is similar to chronological aging in that it is cumulative over time. Women frequently seek effective treatment for their irregular pigmentation as well as other clinical manifestations of photodamaged skin. The facial primer improved scores for the appearance of hyperpigmentation and other photoaging parameters immediately after the first application.

Concealer covers imperfections of the skin. Concealer is often used for any extra coverage needed to cover acne/pimple blemishes, undereye circles, and other imperfections. Concealer is frequently thicker and more-strong than establishment, and gives longer enduring, progressively nitty gritty inclusion just as making a crisp clean base for the remainder of the makeup. This item likewise lights up the skin and applying under the establishment can expel flaws and staining due to skin inflammation scars. In females, specifically, there is a requirement for cosmetic items that can adequately cover the indications of this exceptionally unmistakable skin condition to lessen the passionate effect of the illness. Utilization of cosmetics can likewise build skin inflammation patients' adherence with their restorative regimen, which is evaluated to be poor in half of patients. Maybe the most essential kind of concealer is the restorative sort, and is best in a fluid equation, similar to La-Roche Posay Toleriane 
Teint Corrective Pen, which has remedial hues to help tone down rosiness, blur the presence of hyperpigmentation, and indeed, even concealment any all the more chafing flaws. ${ }^{39-43}$

Foundation is utilized to smooth out the face by covering spots, skin break out, flaws, or uneven skin tone. These are sold in a fluid, cream, or powder, or more as of late in a mousse. Foundation gives sheer, matte, dewy or full inclusion. Foundation preliminary is connected before foundation to round out pores, make a dewy look or make a smoother wrap up. They more often than not come in cream formulas to be connected before foundation as a base. The most-great form of foundation, fluid, offers medium to full inclusion for all skin types, and is a certain flame approach to accomplish a smooth base. ${ }^{8,44-47}$

Face powder sets the foundation and under eye concealer, giving it a matte completion while additionally disguising little imperfections or flaws. It can likewise be utilized to prepare the foundation, with the goal that it remains on longer and make a matte completion. Tinted face powders might be worn alone as a light foundation with the goal that the full face does not look as built up as it could. Free powder arrives in a container, has littler particles (and therefore a better consistency), and for the most part gives lightweight inclusion. It's additionally chaotic and difficult to transport, so this person is intended to remain at home. The contrast between setting powder and completing powder is somewhat shapeless. Numerous organizations utilize these terms reciprocally, so it's incompletely a matter of advertising. ${ }^{27-29,49,50}$

Rouge, blush, or blusher is cheek coloring to draw out the color in the cheeks and influence the cheekbones to seem more characterized. Blush is having a major moment, moving on from makeup pack staple to a featuring job in pretty much every celebrity central beauty look. Rouge comes in powder, cream, and fluid forms. Diverse blush colors are utilized to compliment distinctive skin tones. The antiquated Egyptians were the first to incorporate blush into their beauty customs. The middle Ages saw a drop in the utilization of blush, as red cheeks were related with whores. Amid the 1500 s to the 1700 s, blush was made with lethal synthetic substances. Beginning during the 1900s, as America wound up industrialized, blush started to be mass created and turned out to be a lot more secure to utilize (Figure 7). ${ }^{51-53}$

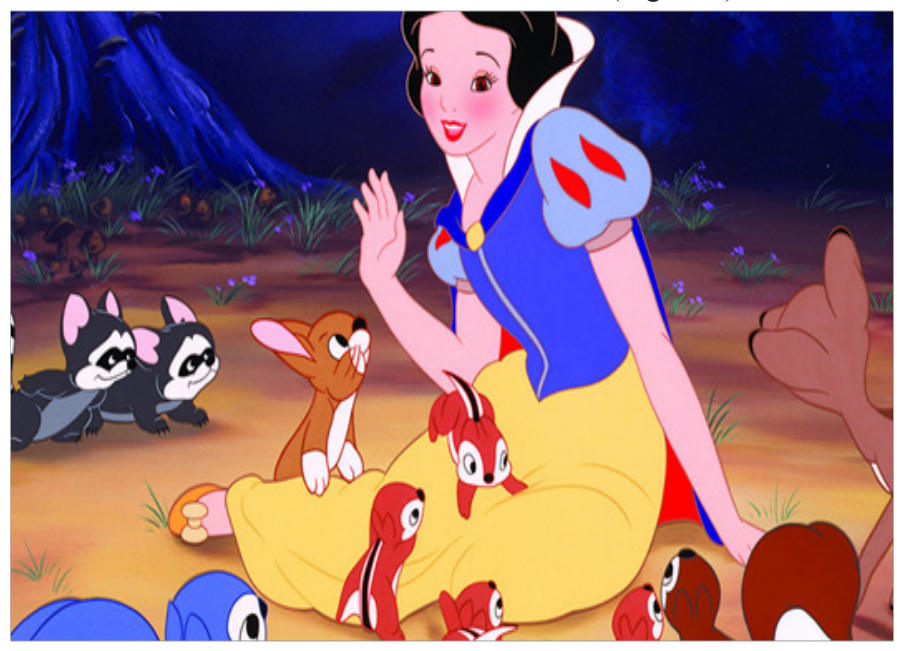

Figure 7 Disney princess, Snow White (Fairy Tale). ${ }^{54,55}$ In the time that Snow White was released it was a common for the majority of women desired to have blush in their faces like her. Rouge originated as a thick paste, and was made from a range of things: from strawberries, to red fruits and vegetable juices, to the powder of finely crushed ochre.As nouns the difference between blush and rouge. is that blush being an act of blushing or blush can be the collective noun for a group of boys while rouge is red or pink makeup to add color to the cheeks; blusher. Blushers, those versatile successors to rouge, help light up a complexion and accent face structure and best features.
Highlighter, used to draw attention to the high points of the face such as the cheekbones, below the eyebrows, nose, upper lip, and collar bones. This product also adds a glow; comes in liquid, cream, and powder forms. It often contains a substance to provide shimmer. Alternatively, a lighter-toned foundation/concealer can be used. ${ }^{56}$

Bronzer gives skin a bit of color and contours the face for a sharper definition or creates a tan-look. Bronzer is considered to be more of a natural look and can be used for everyday wear. Bronzer enhances the color of the face. It comes in either matte, semi-matte/satin, or shimmer finishes (Figure 8). ${ }^{57-59}$

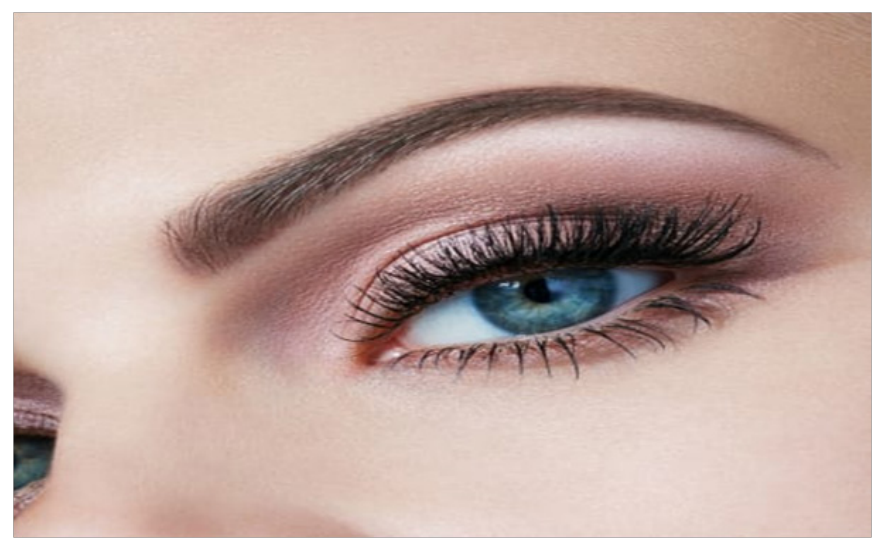

Figure 8 Eye Makeup. ${ }^{60-62}$ Kohl was a broadly utilized conventional cosmetic. It might be an unavoidable wellspring of lead harming in those regions and among people from those regions who have moved to created countries. Regardless of the way that cosmetic items experience rigorous testing to guarantee they are alright for human use; a few clients report mellow discomfort following their application. The cutaneous changes, for example, unfavorably susceptible dermatitis, are very much reported, yet the visual changes related with eye cosmetic utilize are less so. Some pigmented cosmetic items may amass inside the lacrimal framework and conjunctivae over numerous long periods of utilization, yet quick reports of eye discomfort after application are generally normal. Changes to the tear film and its dependability may happen shortly after application, and contact focal point wearers can likewise be influenced by focal point spoliation from cosmetic items. Also, creams utilized in the avoidance of skin maturing are regularly connected around the eyes, and retinoids present in these formulations can affect meibomian organ work and might be a contributing factor to dry eye disease.

Mascara is utilized to darken, stretch, thicken, or attract thoughtfulness regarding the eyelashes. It is accessible in different colors. A few mascaras incorporate sparkle bits. There are numerous formulas, including waterproof variants for those inclined to hypersensitivities or abrupt tears. Usually utilized after an eyelash styler and mascara groundwork. Numerous mascaras have parts to help lashes seem longer and thicker. ${ }^{63-65}$

Eye shadow is a pigmented powder/cream or substance used to emphasize the eye territory, customarily on, above, and under the eyelids. Numerous colors might be utilized without a moment's delay and mixed together to make distinctive impacts utilizing a mixing brush. This is ordinarily connected with a scope of eye shadow brushes; however it isn't extraordinary for elective strategies for application to be utilized, for example, fingers. Be that as it may, it is important to have clean fingers since oils from skin can result in pimples. ${ }^{66,67}$

Eye liner is utilized to improve and extend the clear size or profundity of the eye. For instance, white eyeliner on the waterline and inward corners of the eye makes the eyes look greater and more wakeful. It can come as a pencil, a gel, or a fluid and can be found in practically any color. Then again, dark eyeliner makes eyes look littler, lights up the face and attracts regard for the eyes. ${ }^{66,67}$ 
Eyebrow pencils, creams, waxes, gels, and powders are utilized to color, fill in, and characterize the foreheads. Well-known as of late, the "Instagram look" is making more full eyebrows by filling it, more honed edges, and adding gel to set it. ${ }^{68}$

Nail polish is utilized to color the fingernails and toenails. Straightforward, colorless adaptations may reinforce nails or be utilized as a top or base coat to secure the nail or polish. This can be found in gleam, matte, and powder. ${ }^{68}$

Setting spray is utilized as the last advance during the time spent applying makeup. It keeps connected makeup flawless for extensive stretches. An expansion to setting spray is setting powder, which might be either pigmented or translucent. Both of these items guarantee to shield makeup from absorbing into the skin or liquefying off. ${ }^{69}$

False eyelashes are utilized when misrepresented eyelashes are wanted. Their essential structure for the most part comprises of human hair, mink hair, or engineered materials connected to a slim fabric like band, which is connected with paste to the lash line. Structures shift long and color. Rhinestones, diamonds, and even quills and trim happen on some false eyelash plans. Eyelashes can be obtained in a few medication or beauty supply stores and can be connected with eyelash stick. These eyelashes are not perpetual and can be taken off effectively by tenderly taking them off with fingers. ${ }^{66,67}$

Cleansers or frothing washes are utilized to evacuate abundance earth, oil, and makeup left on the skin. Diverse cleansing items are gone for different sorts of skin, for example, sans sulfate cleansers and turn brushes. Cleansing oil or oil chemical is an oil-based arrangement that can contain, however not really, an emulsifier to take into consideration the oils to delicately emulsify on the skin. Cleansing Oils permitting to give fundamental unsaturated fats to the skin. ${ }^{70,71}$

Toners are utilized in the wake of cleansing the skin to spruce it up, support the presence of one's appearance, and evacuate any hints of chemical, veil, or makeup, also to help restore the skin's regular $\mathrm{pH}$. They are normally connected to a cotton cushion and cleaned over the skin, however can be sprayed onto the skin from a spray bottle. Toners normally contain liquor, water, and home grown concentrates or different synthetic concoctions relying upon skin type whether sleek, dry, or mix. Toners containing liquor are very astringent, and for the most part focused at slick skins. ${ }^{66,72}$

Facial masks are treatments connected to the skin and afterward expelled. Commonly, they are connected to a dry, purified face, staying away from the eyes and lips. Mud based masks use kaolin mud or fuller's earth to transport fundamental oils and synthetic concoctions to the skin, and is ordinarily left on until totally dry. As the earth dries, it absorbs overabundance oil and soil from the surface of the skin and may clear blocked pores or attract comedones to the surface. Due to its drying activities, earth-based masks should just be utilized on slick skins. Strip masks are normally gel-like in consistency, and contain acids or shedding specialists to help shed the skin, alongside different fixings to hydrate, demoralize wrinkles, or treat uneven skin tone. They are left on to get and after that delicately stripped dry. They ought to be evaded by individuals with dry or delicate skin, as they will in general be very drying. Sheet masks are a generally new item that is ending up amazingly well known in Asia. Sheet masks comprise of a slim cotton or fiber sheet with openings cut out for the eyes and lips and slice to fit the forms of the face, onto which serums and skin treatments are brushed in a flimsy layer; the sheets might be absorbed the treatment. Masks are accessible to suit practically all skin types and skin protests. Sheet masks are faster, less muddled, and require no particular learning or equipment for their utilization contrasted with different sorts of face masks, however they might be hard to discover and buy outside Asia (Figure 9). ${ }^{73-75}$

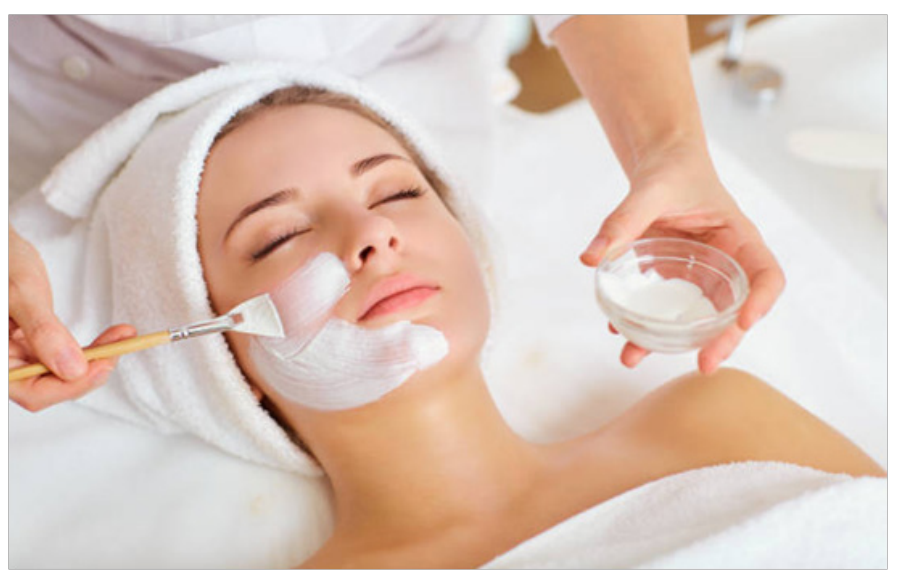

Figure 9 Facial Treatment. ${ }^{76-79}$ Facial masks are the most prevalent cosmetic products utilized for skin rejuvenation. Facial masks are divided into four groups:
i. Sheet masks
ii. Peel-off masks;
iii. Rinse-off masks; and
iv. hHydrogels

Each of these has some advantages for specific skin types based on the ingredients used.Peel-off facial masks are known for their unique characteristics inherent to the use of film-forming polymers that, after complete drying, create a very cohesive plastic layer allowing for the manual removal of the product without leaving any residue. Most clay-based products on the market consist only of dried clay powder that needs to be moistened prior to use.After facial application, the product dries naturally, forming a sandy-cracked material due to the low cohesion between the dried particles. The most interesting effects of aloe vera in topical use are anti-inflammatory, antiseptic, antioxidant, and regenerative. It has been demonstrated that the association of green clay and aloe vera exerts a beneficial synergistic effect when it comes to developing a facial mask as a regenerative aid.

Exfoliants are products that help slough off dry, dead skin cells to improve the skin's appearance. This is accomplished either by utilizing mellow acids or different synthetic concoctions to extricate old skin cells, or rough substances to physically scour them off. Shedding can level out patches of harsh skin, improve course to the skin, clear blocked pores to dishearten skin break out and improve the appearance and mending of scars. Concoction exfoliants may incorporate citrus extract (from citrus organic products), acidic corrosive (from vinegar), malic corrosive (from natural product), glycolic corrosive, lactic corrosive, or salicylic corrosive. They might be fluids or gels, and could possibly contain a grating to evacuate old skin cells a while later. Grating exfoliants incorporate gels, creams or salves, just as physical items. Loofahs, microfiber fabrics, common wipes, or brushes might be utilized to peel skin, basically by scouring them over the face in a roundabout movement. Gels, creams, or moisturizers may contain a corrosive to urge dead skin cells to release, and a grating, for example, microbeads, ocean salt, sugar, ground nutshells, rice wheat, or ground apricot pieces to scour the dead cells off the skin. Salt and sugar scours will in general be the harshest, while cleans containing globules or rice grain are normally delicate. ${ }^{73,80}$

Contouring is intended to offer shape to a zone of the face. The point is to upgrade the normal shading on the face to give the fantasy 
of a more characterized facial structure which can be adjusted to inclination. More brilliant skin colored makeup items are utilized to 'feature' regions which are needed to attract thoughtfulness regarding or to be gotten in the light, while darker shades are utilized to make a shadow. These light and dark tones are mixed on the skin to make the deception of a more unequivocal face shape. It very well may be accomplished utilizing a "shape palette" - which can be either cream or powder (Figure 10). ${ }^{57,81}$

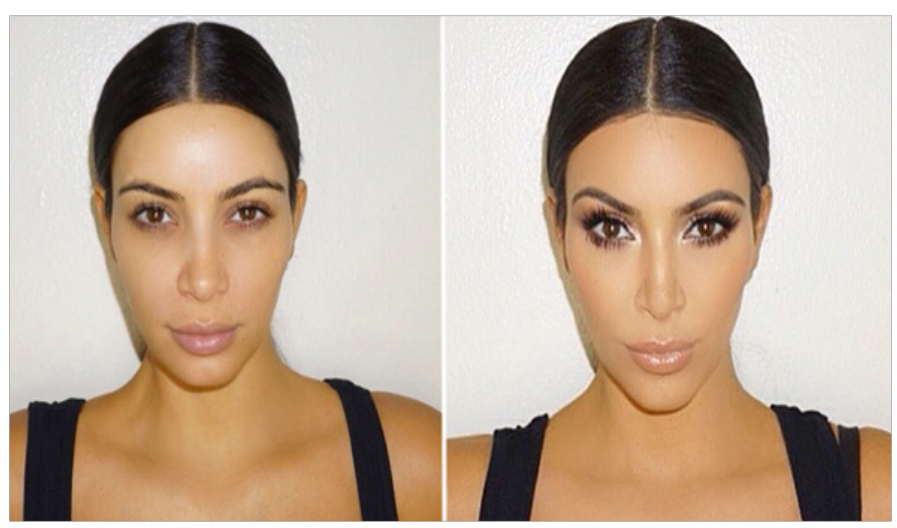

Figure 10 Contouring. ${ }^{82}$ Contouring is the newest makeup craze that people just can't get enough of! This trend, made famous by none other than the Kardashian sisters, was created to make your face appear slimmer and more sculpted.The basic premise of it is to highlight the areas of face that someone would like to bring out, while shading in the parts she wants to make thinner.

Moisturizers are creams or lotions that hydrate the skin and help it to retain moisture; they may contain essential oils, herbal extracts, or chemicals to assist with oil control or reducing irritation. Night creams are normally more hydrating than day creams, however might be excessively thick or substantial to wear amid the day, subsequently their name. Tinted lotions contain a little measure of foundation, which can give light inclusion to minor imperfections or to try and out skin tones. They are typically connected with the fingertips or a cotton cushion to the whole face, staying away from the lips and zone around the eyes. Eyes require an alternate sort of lotion contrasted and the remainder of the face. The skin around the eyes is amazingly dainty and delicate, and is frequently the primary zone to hint at maturing. Eye creams are ordinarily light moisturizers or gels, and are typically delicate; some may contain fixings, for example, caffeine or Vitamin $\mathrm{K}$ to diminish puffiness and dark circles under the eyes. Eye creams or gels ought to be connected over the whole eye region with a finger, utilizing a tapping movement. Finding a cream with SPF is valuable to avert maturing and wrinkles. ${ }^{73,74}$

Soaps composed of long chain fatty acid alkali salts with a $\mathrm{pH}$ of between 9 and 10. Utilization of cleanser with high $\mathrm{pH}$ causes an expansion in skin $\mathrm{pH}$, which thus causes an increment in dehydrative impact, fractiousness and adjustment in bacterial flora. The majority of cleansers and shampoos accessible in the market don't reveal their $\mathrm{pH}$. Glycerin bars/straightforward bars: utilized wildly in our nation in winter. They contain humectant-glycerin to counter the drying impacts of cleanser. Super-fatted cleansers: contain more noteworthy measure of lipids, for example, triglycerides, lanolin, paraffin, stearic corrosive, or mineral oils which give a defensive film on the skin. Deodorant cleansers/antibacterial cleansers: contain antibacterial specialists, for example, triclosan, triclocarban, or carbanile to restrain the development of microbes and along these lines odor. ${ }^{75,76}$

Shampoos are used primarily to clean the scalp of dirt and other environmental pollutants, sebum, sweat, desquamated corneocytes (scales), and other greasy residues including previously applied hair care products such as oils, lotions and sprays. It is anything but difficult to formulate a shampoo which will expel the majority of the sebum and earth from the hair and scalp, yet this will leave the hair, fuzzy, dry, unmanageable and ugly. Cleanser presently is additionally expected to have an auxiliary capacity which serves to condition and decorate hair and to alleviate the aggravated scalp skin in conditions like seborrheic dermatitis. The test is to expel simply enough sebum to enable the hair to seem clean and desert enough molding operators to leave the hair delicate, sparkling and sensible. This exercise in careful control between great cleaning and enhancing the hair is a craftsmanship accomplished by blending different fixings in the correct proportion in the cleanser arrangement. The cutting edge propels in science and innovation have made it conceivable to supplant the cleanser bases with complex formulation which contain cleansing operators, molding specialists alongside functional added substances, additive, stylish added substances and at times even restoratively dynamic fixings. ${ }^{77-81}$

Conditioners are used to decrease friction, detangle the hair, minimize frizz and improve combability. Conditioners act by neutralizing the electrical negative charge of the hair fiber by including positive charges and by greasing up the fingernail skin that decreases fiber hydrophilicity. They contain hostile to static and greasing up substances that are isolated into 5 principle gatherings: Polymers, oils, waxes, hydrolyzed amino acids and cationic atoms. The most dynamic and utilized conditioner operator is a silicone. There are distinctive sorts of silicones with various testimony, adherence and wash out limit which will prompt diverse performances of the conditioner. The perfect conditioner is fit for restore the hydrophobicity of the fiber and kills the electricity produced via friction. Contingent upon the limit of entering the fiber, the conditioner may achieve the fingernail skin surface or the internal piece of the cortex..$^{78,81}$

Deodorant is one of the most commonly used cosmetic products, with millions of consumers applying these products to their axilla every day. Deodorants are utilized to veil odor; while, antiperspirants are utilized to lessen the measure of perspiration created. These two exercises are frequently joined into single items. While deodorants are viewed as cosmetic items since they don't change the capacity of the skin, antiperspirants are named tranquilizes and are therefore subject to tenets and guidelines put forward by the FDA. The dynamic fixing in antiperspirants is typically aluminum based, which decreases sweat by causing block of the eccrine organs. Deodorants work by two distinct systems - antimicrobial specialists decline the quantity of microorganisms that produce unstable odoriferous substances and scents spread any odors that are delivered. As of late, normally happening zeolite minerals, as potassium alum or ammonium alum precious stones have been promoted as every regular option in contrast to deodorants and antiperspirants. These items are sold in strong precious stone form. The shopper is told to wet the precious stone and apply the item to the underarm region to anticipate odor. Albeit no examination has been distributed assessing the component of activity of these items, the organization that business sectors them, Crystal Body Deodorant (French Transit, Ltd., Burlingame, California), guarantees that the mineral salts make an environment in which microscopic organisms can't endure. ${ }^{82,83}$

\section{Products classified as therapeutics}

Antiperspirants help to reduce the production of sweat. Aluminium salts-the active ingredient found in antiperspirants-dissolve into the moisture on the skin's surface. This forms a gel, which temporarily sits on top of the sweat gland, reducing the amount of sweat released. 
Antiperspirants that contain alcohol also help the active ingredient to dry faster and create a pleasant, cool feeling. An antiperspirant can also be a deodorant, because it can help to control sweat and contain a fragrance at the same time. But deodorants only mask body odor; they don't help to prevent sweating. ${ }^{77,84,85}$

Anti-dandruff shampoo- Dandruff (pityriasis capitis) is a chronic scalp condition characterized by scaling and sometimes itching and redness. Shampoos containing antifungal agents are used to control the scaling condition. Regular use of anti-fungal shampoos represents a proven therapeutic strategy to improve the most common symptoms of flakes and itch. The therapeutic efficacy of a product based on a complex delivery vehicle such as a shampoo must be considered from a full-product perspective rather than just the active system as the nonactive components of the composition will often play a significant role in the overall product pharmacology and resultant efficacy ${ }^{86-88}$

\section{Household products}

Toothpaste is a paste or gel to be used with a toothbrush to maintain and improve oral health and aesthetics. Since their presentation a few thousand years back, toothpaste formulations have advanced extensively-from suspensions of pounded egg shells or slag to complex formulations with frequently more than 20fixings. Fluoride is the most important helpful substance utilized in toothpastes, adding with the impact of mechanical tooth brushing on dental caries control. The utilization of fluoride toothpaste to lessen caries in youngsters and grown-ups is unequivocally founded on proof, and is subject to the fixation (least of $1000 \mathrm{ppm} \mathrm{F}$ ) and recurrence of fluoride toothpaste use (2'/day or higher). The danger of dental fluorosis because of toothpaste ingestion by kids has been overestimated, since there is no proof that:

a) Fluoride toothpaste use ought to be deferred until the age of 3-4 or more established,

b) Low-fluoride toothpaste stays away from fluorosis and

c) Fluorosis detrimentally affects the personal satisfaction of people presented to fluoridated water and toothpaste.

Among other restorative substances utilized in toothpastes, there is proof that triclosan/copolymer diminish dental biofilm, gum disease, periodontitis, math and halitosis, and that toothpastes containing stannous fluoride decrease biofilm and gum disease. ${ }^{89-92}$

A mouthwash may be defined as a non-sterile aqueous solution used mostly for its deodorant, refreshing, or antiseptic effect. Mouthwashes or washes, when utilized as an aide to ordinary oral cleanliness techniques, for example, flossing. The primary reference to mouth wash as a formal practice is credited to Chinese medication, around 2700B.C.E., to treat the sicknesses of the gums. Mouthwashes apply unfriendly impacts on teeth, gums and mucous layer of oral pit and their broad use is being censured. Ponder uncovered that harm to DNA increments numerous folds when diverse mouthwashes are consolidated. Fundamental oils of six zest plants (dark pepper, clove, dark seasam, cinamon, carom seeds and cumin) were assessed for having hostile to mutagenic property. These basic oils were found viably defensive against the DNA harming impact of mouthwashes however couldn't restrain it totally. Dark pepper, clove, dark seasam, cinamon, and cumin were more grounded defensive when contrasted with carom seeds. ${ }^{25,93-96}$

Detergents- Performing family unit cleaning chores include the utilization of concoction cleansers; these are usually accepted to give cleaner and more secure families. Word related wellbeing contemplates have related wellbeing dangers with cleansers, including respiratory and skin issues. Women are the major clients of family cleansers, as they are as a rule the essential homemakers. Cleanser taking care of procedures including storage, use, and prudent steps influence women's presentation to synthetic cleansers and in this way influence their wellbeing. Studies researching the behavioral part of substance presentation to cleansers at the household level are rare. The distinctive classes of crude materials are surfactants, manufacturers, dying operators, proteins, and minors which expel earth, stain, and soil from surfaces or materials gave them charming feel and odor. The physico-substance properties of surfactants make them appropriate for clothing purposes. Clothing cleanser has customarily been a powdered or granular strong, yet the utilization of fluid clothing cleansers has bit by bit expanded throughout the years, and nowadays utilization of fluid cleanser squares with or even surpasses utilization of strong cleanser. This survey paper depicts the history, organization, types, instrument, utilization, environmental impacts and utilization of clothing cleansers. Visit presentation to antimicrobial family unit items has been theorized to prompt unfavorably susceptible sicknesses in kids. ${ }^{97-101}$

Baby Products- In spite of the fact that the U.S. pediatric skin care showcase is a $\$ 1.7$ billion industry, little is known in regards to the use example of skin care items in extremely youthful kids. The characteristic infant skin-care items were very much endured by babies and little children when utilized alone or as a major aspect of a skin-care regimen. Following birth, the skin boundary of solid, full-term neonates is equipped, yet skin-hindrance work keeps on creating through at any rate the principal year of life. This creating condition of newborn child skin results in baby skin being defenseless to dryness and disturbance from outside factors, for example, chilly climate and wind, just as brutal topical skin-care items. Therefore, it is important that newborn child cleansers and lotions be very much endured and not upset the stratum corneum. Newborn child skin is additionally presented to different factors, for example, salivation, nasal emissions, pee, defecation (counting fecal proteins), and earth, which can be aggravations and result in interruption of the skin hindrance. Lower-salary families reported a higher recurrence of item utilize and were less inclined to buy scent free items or ones that were made for touchy skin. Because of normal day by day presentation to these outer factors, appropriate skin cleansing and insurance of the baby skin hindrance are fundamental to the upkeep of skin-boundary work. Late examinations recommend that some phthalates can modify human male regenerative development, affiliation was most grounded in youthful newborn children, who might be more powerless against developmental and conceptive poisonous quality of phthalates given their juvenile metabolic framework capacity and expanded dose per unit body surface region. There was some proof to recommend that day by day utilization of full-body emollient treatment may lessen the danger of atopic dermatitis in high hazard babies with a hereditary inclination to dermatitis; in any case, the utilization of olive oil or sunflower oil for infant dry skin may unfavorably influence skin obstruction work. ${ }^{102-108}$

Toiletries- More noteworthy accentuation on tidiness has prompted augmenting utilization of disinfectants and other cleaning operators in the home. Genuine picture is, an expected 2.3billion individuals needed access to improved sanitation offices, worldwide found in a recent report. Insufficient access to sanitation and cleanliness offices is known to be a main source of morbidity and mortality, especially in low-pay nations. Truth be told, around $10 \%$ of the 
worldwide weight of illness is believed to be ascribed to lacking Water, Sanitation, And Hygiene (WASH), which is to a great extent driven by expanded introduction to human pathogens transmitted by means of the fecal-oral course. An unwanted impact (UE) of a cosmetic item is a destructive response inferable from its normal or sensibly foreseeable use. Nonetheless, the information of UEs, at the populace level, is restricted by the nonappearance of formal and dependable cosmetovigilance frameworks, which in any case are described by underreporting. Triclosan is a generally utilized antimicrobial pesticide; in truth it's so broadly utilized that there is worry that triclosan could be adding to making microscopic organisms impervious to anti-infection agents. Triclosan not just aggravates the skin; it might likewise advance disease and disturb the endocrine framework. Toluene is a harmful concoction normally found in nail items and hair colors. It is additionally recorded on marks as benzene, toluol, phenylmethane, or methylbenzene. Toluene can influence the respiratory and focal sensory systems, harm the liver and kidneys, and cause birth deserts and unconstrained abortion. Most cosmetics and toiletries items contain aromas, which are regularly marked as 'scents,' and do exclude the rundown of synthetic concoctions they are included. Scents can add to air contamination and medical problems, for example, hormone disturbance, asthma, hypersensitivities, and headaches. Parabens are estrogen-imitating additives found in numerous cosmetics and other body-care items. An investigation by the Centers for Disease Control and Prevention demonstrated that the vast majority of the members tried for paraben introduction came up positive. Studies have appeared potential connection between paraben presentation and the expansion of bosom malignant growth cells. The European Union considered butylated hydroxyanisole (BHA) hazardous for use in aroma, however BHA can at present be found in cosmetics and other individual consideration items in the United States. The National Toxicology Program considers BHA a cancer-causing agent and creature thinks about have demonstrated it harms the regenerative framework. Found in several individual consideration items and other product, from shower draperies to wood wraps up. Most Americans tried by the Centers for Disease Control and Prevention in the National Health and Nutrition Examination Survey amid 2003 to 2004 demonstrated the metabolites of a few phthalates in their pee. Phthalates are viewed as harmful to normal development and the regenerative framework, and can possibly cause endocrine disturbance and malignant growth. A significant part of the market is overwhelmed by huge brand proprietors. The kind of items in the family unit sectors frequently coordinates the bundling material decision with some more forceful dye based items utilizing HDPE. Plastic waste is likewise created as a non-biodegradable waste, which can cause environmental contamination from unsanitary transfer and lethal leachates and gases, particularly carbon monoxide and dark smoke delivered from open consuming. ${ }^{109-121}$

\section{Safety issues of cosmetics}

Cosmetic items are every now and again connected to the skin by an extensive number of individuals, yet some contain exacerbates that are possibly harmful, if absorption through the skin is adequate. Makeup, cleanser, skin salve, nail polish, and other individual consideration items contain synthetic fixings that need wellbeing information. Moreover, a portion of these synthetic compounds have been connected in creature concentrates to male genital birth abandons, diminished sperm tallies, and changed pregnancy results. There is no authoritative proof for similar impacts in people; however across the board presentation, essentially to phthalates, has been appeared to happen. Phthalates, as key parts in plastics, show up in numerous buyer items. The primary phthalates in cosmetics and individual consideration items are dibutyl phthalate in nail polish, diethyl phthalate in scents and moisturizers, and dimethyl phthalate in hair spray. Regularly, their essence isn't noted on marks. ${ }^{122}$ For genuine medical issues to emerge, presentation to these quickly clearing mixes must happen regularly. Two such classes of mixes are the phthalate plasticizers and parabens, the two of which are utilized in numerous individual consideration items, a few drugs, and even nourishments and sustenance safeguarding. The phthalates are regularly found in nourishments and family unit dust. Despite the fact that they have generally short half-lives in people, phthalates have been related with various genuine medical issues, including barrenness, testicular dysgenesis, corpulence, asthma, and sensitivities, just as leiomyomas and bosom malignant growth. Parabens, which can be dermally absorbed, are available in numerous cosmetic items, including antiperspirants. Their estrogenicity and tissue nearness are a reason for concern with respect to bosom malignancy. Fortunately, these mixes are moderately simple to dodge and such advances can result in emotional decreases of urinary dimensions of these mixes. ${ }^{123} \mathrm{~A}$ broad number of cosmetic items are connected topically close by the human bosom once a day, regularly on various occasions multi day, including underarm enemy of perspirant/deodorant items yet additionally body salves, body sprays, saturating creams, bosom firming/upgrading creams and sun care items. These items are not washed off but rather left on the skin, taking into consideration constant dermal introduction, absorption and testimony into basic tissues, which might be additionally expanded by scraped areas in the skin made by shaving. Clinical examinations going back decades report a disproportionately high number of female bosom malignant growths originating in the upper external quadrant of the bosom, and despite the fact that this is ascribed to a more prominent measure of epithelial tissue in that district, it is additionally the territory to which underarm cosmetic items are connected. Early investigations reported $31 \%$ of diseases in the upper external quadrant, yet later examinations during the 1990s report up to $61 \%$. On the premise that antiperspirant formulations are intended to square underarm perspiration conduits and bosom blisters emerge from blocked bosom channels in the nearby district of the body. ${ }^{124}$ The percutaneous absorption of N-nitrosodiethanolamine (NDELA), a debasement in numerous cosmetic items, has been assessed in dispersion cells utilizing extracted human skin. ${ }^{125}$ The Cosmetic Ingredient Review (CIR) program was set up in 1976 by the Cosmetics, Toiletry, and Fragrance Association, with the support of the Food and Drug Administration (FDA) and the Consumer Federation of America (CFA). CIR performs free, master surveys to decide whether fixings utilized in cosmetics are protected. CIR staff gets ready rundowns of accessible information and the CIR Expert Panel surveys the information in open, open gatherings. In the event that more information is required, demands are made. Unpublished investigations might be given, yet turned out to be open and accessible for survey once abridged in CIR wellbeing assessments. Provisional determinations are supported with a reason and open comment is looked for. Mulling over any info, a last security assessment monograph is issued. These monographs are submitted for production in the companion looked into International Journal of Toxicology. Hair colors speak to an important item category looked into by CIR. In considering hair colors, the CIR Expert Panel audits experimental and clinical information explicit to the specific compound structure of every hair color and surveys epidemiologic examinations that address hair color utilize that are less explicit. CIR Expert Panel presumed that the accessible epidemiologic investigations are lacking to finish up there is a causal connection between hair color use and 
malignant growth and opposite end focuses. It is unavoidable that new information will end up accessible concerning elements for which wellbeing assessments were finished in the beginning of the program. To think about new information, the CIR Expert Panel has organized a re-audit program. Sodium lauryl sulfate (SLS), formaldehyde, and parabens are examined as models. Wellbeing assessments as of now in progress are recorded, alongside high-priority fixings from which new work will be picked. Albeit supported by the cosmetics business, the CIR program has stayed free in its basic leadership, in light of its open, open procedure; the trustworthiness of the master board individuals; the investment of the FDA and the CFA; and the collaboration of the cosmetics business. ${ }^{126}$ Throughout the years, some dissident gatherings have focused on cosmetics as conceivable human wellbeing dangers, guaranteeing that cosmetic fixings are not enough tried for security and may present dangers to consumers. The gatherings assert that industry rehearses identified with wellbeing testing are defective, that there is little government oversight, and that cosmetics contain malignancy causing synthetic substances and different toxicants.

\section{A critical review of the scientific data related to these claims indicates}

a. Industry has the primary responsibility to ensure that all ingredients, preservatives, and co-formulants used in products are safe for their intended uses.

b. The US FDA has regulatory oversight of the cosmetic industry. Its authority includes the banning or restriction of ingredients for safety reasons.

c. The Cosmetic Ingredient Review (CIR), an independent, scientific review board, critically evaluates chemical ingredients used in cosmetics and publishes the results of its findings in the peer-reviewed literature.

d. Health-related allegations about cosmetic ingredients are generally based on the results of high-dose laboratory testing in animals and have little relevance for humans. As true now as when Paracelsus said it in the 16th century, "It is the dose that makes the poison."

e. Chemicals such as phthalates, parabens, bisphenol A (BPA) and triclosan (TCS), used in a wide variety of consumer products, are suspected endocrine disrupters although their level of toxicity is thought to be low. Combined exposure may occur through ingestion, inhalation and dermal exposure, and their toxic as well as combined effects are poorly understood.

f. Animal and human physiology differs in crucial ways, further invalidating simplistic attempts to extrapolate rodent testing to human health risks.

The cosmetic industry should be encouraged to publish more of its toxicity studies and safety evaluations, which would aid in dispelling the uncertainty that some consumers have about cosmetic safety. ${ }^{127,128}$ Since the FDA does not specify acceptable levels, the cosmetic industry generally follows the guidelines of the Personal Care Products Council (PCPC) (formerly the Cosmetic, Toiletry, and Fragrance Association (CTFA)) regarding the level of microbial contamination and the absence of pathogens. ${ }^{129}$

\section{Exhibit 2 FDA in Action ${ }^{130-137}$}

a. Under a structure originally established in 1938 that places regulation of cosmetics under the Food and Drug Administration
(FDA), cosmetics manufacturers in the United States are not required to register their products or forward consumer complaints to the FDA, leading to broad under-reporting of adverse events. The FDA has limited authority to mandate product recalls.

b. In July 2018, Johnson \& Johnson was ordered to pay a \$4.96billion settlement to 22 women who found asbestos in talc in baby powder caused their ovarian cancer.

c. Guthy-Renker, the manufacturer of WEN hair products, settled a class-action lawsuit for \$26million after consumers said it caused rashes and hair loss.

d. After decades of use in soaps, the FDA finally banned triclosan from soap in 2016 over concerns about its long-term safety and contribution to antibiotic-resistant bacteria. Unfortunately, it is still used in many products like toothpaste, mascara, and foundation.

\section{Skin and other sensitivity issues of cosmetics}

Human skin is the front line of defenses against external infectious or toxic substances, and is an environmental habitat that various microorganisms, including bacteria, fungi, yeasts, and viruses, can colonize. Human skin is a complex ecosystem with different micro environmental conditions, and in this manner, skin microbial networks are extremely assorted and complex. Skin structures, for example, hair follicles, sebaceous organs, eccrine and apocrine perspiration organs just as subepidermal skin compartments, give particular natural specialties that are colonized by their very own remarkable skin microbiota. The present comprehension is that a large portion of these skin microorganisms are innocuous or commensal organisms that assume fundamental jobs in restraining colonization by pathogenic microorganisms or tweaking inborn and versatile resistant frameworks. ${ }^{138}$ Skin affectability isn't the main issues with cosmetics. Beauty salon workers and consumers endured such wounds as eye and sensory system disorders, respiratory tract issues, chest torment, spewing and rash because of utilizing the straightener however it stays available in light of the fact that the FDA isn't authorized to review cosmetics. ${ }^{139}$ Delicate skin is less tolerant to visit and delayed utilization of cosmetics and toiletries. It is self-analyzed and regularly unaccompanied by any undeniable physical indications of disturbance. With the adjustment in way of life and furthermore with expanded opportunity to utilize numerous new brands of cosmetics and toiletries, there has been an expansion in females grumbling of one of a kind sensation in their facial skin. Touchy skin exhibits as hurting, consuming, stinging, tingling, or potentially tight sensation in their facial skin. The condition is found in more than half of women and $40 \%$ of men, making a sizable interest for items intended to limit skin affectability. Great quantities of obtrusive and non-intrusive tests are intended to assess and foresee the delicate skin. Management incorporates rules for choosing reasonable cosmetics and toiletries in delicate skin people. ${ }^{140}$ In Europe, $1 \%$ of the populace is assessed to be adversely affected by aromas and $2-3 \%$ to elements of cosmetics; $10 \%$ of outpatients fix tried for cosmetics sensitivity were observed to be sure. Allergenic elements of cosmetics can be aromas, hair color, additives, cancer prevention agents, emollients, surfactants, UV absorbers, pigments or pitches utilized in nail cosmetics. Among standard allergen arrangement, eight substances are identified with cosmetics; in Japan in 2003, p-phenylenediamine (hair colors) prompted hypersensitive responses with the most noteworthy rate of $7.9 \%$ in outpatients' fix tried. Cosmetic hypersensitivity indications will in general be gentle aside from those brought about by hair color. ${ }^{141}$ 


\section{Natural products for cosmetic uses}

Some common items have been appeared to profit the skin, particularly for the restoration of skin obstruction. Dead Sea mud and water, balneotherapeutic water arrangements, remote ocean wipes, milk, and pearl, for models, have been utilized in old to present day formulations for topical application to give solid ever-enduring skin. Results were not in every case all around documented; however the impacts have been watched and activated numerous examinations. The Dead Sea, the most profound and most saline lake on earth, has been known from scriptural occasions for its recuperating properties. The point of this deliberate audit was to show fundamentally the dimension of proof for the cases of remedial impacts of Dead Sea treatments in a few rheumatologic infections and psoriasis just as to survey these treatments' wellbeing. ${ }^{142}$ Among numerous parts inside these materials, calcium is one remarkable fixing in like manner. Plants and normal items with skin-brightening impacts are picking up enthusiasm among consumers and analysts since they are seen to be milder, more secure, and more advantageous than engineered options. ${ }^{143}$ Organic exercises of plants and normal concentrates are therefore accessible for cosmetic formulators and dermatologists inspired by normally determined elements for skin hyperpigmentation treatment and as per the consumers' inclinations and desires upon common cosmetic items. Photo-aging is a main worry for patients and a large number of these patients will express a longing to use regular fixings as treatment. Mushrooms, feverfew, green tea, licorice, olive oil, soy, and espresso berry have been appeared to have cell reinforcement properties and may assume a job in the treatment and counteractive action of photoaging. ${ }^{144}$ Organic mixes for which dermatologic and cosmetic applications have developed include: olive oil, chamomile, colloidal oats, oat bit separate, feverfew, acai berry, espresso berry, curcumin, green tea, pomegranate, licorice, paper mulberry, arbutin, and soy. Huge numbers of these organic sources offer naturally dynamic segments that require further in vitro and in vivo examination with respect to over-the-counter items dependent on this fixings. ${ }^{145}$ The characteristic infant skin-care items were very much endured by newborn children and babies when utilized alone or as a major aspect of a skin-care regimen. Albeit conventional skincleansing, cream, and cleanser items still include a substantial offer of the individual consideration showcase, expanding quantities of consumers and medicinal services experts have started examining items and item names, which has made a sizeable market for items that contain regular fixings. Following birth, the skin obstruction of solid, full-term neonates is skilled, yet skin-hindrance work keeps on creating through in any event the primary year of life. This creating condition of newborn child skin results in baby skin being defenseless to dryness and disturbance from outside factors, for example, chilly climate and wind, just as brutal topical skin-care items. Therefore, it is important that newborn child cleansers and lotions be all around endured and not disturb the stratum corneum. Newborn child skin is likewise presented to different factors, for example, spit, nasal discharges, pee, defecation (counting fecal proteins), and earth, which can be aggravations and result in disturbance of the skin obstruction. Because of normal every day introduction to these outside factors, appropriate skin cleansing and security of the newborn child skin boundary are fundamental to the support of skin-obstruction work. ${ }^{146}$ Nutraceuticals speak to a promising methodology for averting, deferring, or limiting untimely maturing of the skin and furthermore to lighten certain skin disorders. Among them, bioactive peptides and oligosaccharides, plant polyphenols, carotenoids, nutrients and polyunsaturated unsaturated fats are the most generally utilized fixings. Supplementation with these items has appeared of affecting the indications of maturing and assurance against UV radiation maturing in a few human preliminaries. ${ }^{147}$ Conventional formulation methods have concentrated on making the best performing items at the most reduced expense. Little respect has been given to the wellspring of the beginning crude materials. Be that as it may, issues of manageability, purchaser wants and regulatory weights have prompted the requirement for the development of cosmetics utilizing fundamentally plant-based, sustainable resourced crude materials. This shows a unique test to formulators as the beginning materials regularly don't work just as conventional engineered fixings. Since the cosmetics and individual consideration industry isn't directed, different organizations have offered clashing positions on institutionalized rules for characteristic and organic cases. To improve correspondence on this point, it will therefore wind up important to separate cases with respect to the instinctive nature of fixings from the view of wellbeing. Wellbeing is inborn in the crude materials utilized for formulating; paying little respect to their origin and in the collaborations among fixings-for more than 50years, the industry has worked hard to monitor the security of items available, supported by the US Food and Drug Administration (FDA). Also, as of late, more governmental offices, for example, the FDA, the US Department of Agriculture (USDA) and the Council of Europe's Committee of Experts on Cosmetic Products have played a proactive job in sorting out the implications of normal and organic for the cosmetics and individual consideration industry. Such organizations go about as a more clearly logical point of convergence in choosing what fixings are alright for use in cosmetic items. Moreover, a few organizations at present are monitoring the security of cosmetics and individual consideration fixings, for example, the Cosmetic Ingredient Review (CIR) board. ${ }^{148}$

\section{Targeted cosmetics}

Skin compartments customarily focused by cosmetic activesepidermis and dermis - are anchored and fed by the hidden hypodermis, which therefore ought to be a key focus for skinreviving formulations. Nonetheless, given the trouble to reach even the shallow layers of the skin, and to its 'unglamorous' greasy piece, the regenerative capability of hypodermis remains to a great extent undiscovered. Nutraceutical grade cosmetics can possibly instigate flag transduction pathways in facial hypodermis, bringing about enemy of maturing impacts all through all skin compartments, including dermal and epidermal layers. ${ }^{149}$ Skin brightening items are monetarily accessible for cosmetic purposes so as to acquire a lighter skin appearance. They are likewise used for clinical treatment of pigmentary disorders, for example, melasma or post-inflammatory hyperpigmentation. Brightening operators act at different dimensions of melanin creation in the skin. A considerable lot of them are known as aggressive inhibitors of tyrosinase, the key chemical in melanogenesis. Others hinder the development of this chemical or the transport of pigment granules (melanosomes) from melanocytes to encompassing keratinocytes. In the Western culture it is still viewed as alluring to acquire a (bronze) tan. In spite of alerts about the results of over the top sun or UV introduction, the counterfeit tanning business has extended unequivocally in the most recent decades. In the Eastern world, be that as it may, a century in length convention exists whereby a light composition is viewed as proportional to youth and beauty. Development of arrangements for dying hyper pigmented sores or to securely accomplish by and large brightening is one of the difficulties for cosmetic industry. As of late, the enthusiasm for skin brightening has developed tremendously. ${ }^{150}$ It is evaluated around $15 \%$ of the world populace put resources into skin brightening operators with 
Asia is being commanded. Worldwide industry examiners (GIA) have anticipated that the all inclusive market for skin lighteners will reach \$23billion by 2020, driven by new markets in Asia, especially India, Japan and China. According to the SIRONA biochem (a biotechnology organization, Vancouver, British Columbia) report, around \$13billion spent on skin care items and cosmetics in Asia Pacific's. In India alone, it is evaluated that $\$ 432$ million was spent in 2010 on skin helping creams and skin care specialists. An ongoing study demonstrated that $80 \%$ of Indian men use reasonableness creams and the quantity of purchaser's are becoming $18 \%$ yearly. The atomic component of these skin helping operators is to lessen the melanin, which is the principle wellspring of skin color. ${ }^{151,152}$ The quantity of patients that visit dermatologists with pigmentary disorders is huge. Patients are frequently overpowered with various over-the-counter skin helping specialists, numerous without clinical proof of viability. Plant and regular fixings have turned out to be prominent as depigmenting items and give an option in contrast to the present highest quality level, hydroquinone. In spite of the requirement for more long haul, all around planned, randomized, controlled investigations, a few plant and normal fixings do demonstrate introductory guarantee in treating disorders of hyperpigmentation dependent on the aftereffects of clinical preliminaries. These fixings are AA, soy, lignin peroxidase, ascorbic corrosive iontophoresis, arbutin, ellagic corrosive, licorice removes, niacinamide, and mulberry. Notwithstanding appearing in treating hyperpigmentation, these specialists additionally give more prominent knowledge into the pathogenesis of dyschromia, hence improving our comprehension of the numerous complexities of pigment disorders. ${ }^{153}$ Cellulite is a genuine cosmetic worry for the greater part of the $90 \%$ of women influenced by it. The phenomenon is most normally observed on hips, posterior, and thighs however can likewise contact different territories, including the abdomen. Up to $90 \%$ of lady, more than 20years old are influenced at different degrees, against just $2 \%$ of men. Cellulite is viewed as a normal condition by the therapeutic network, yet it is a genuine cosmetic worry for most women influenced by it. It is an intricate phenomenon that requires a mind boggling approach, and almost certainly, no single fixing is exclusively in charge of the advantages reported. A few disorders have likewise been related with cellulite, for example, venous deficiency, kidney issues, metabolic irritations, and gastrointestinal modifications. ${ }^{154}$ Numerous cosmetic items are accessible in spray form. Despite the fact that the primary focuses of these items are the skin and hair, spraying prompts the parceling of the item between the objectives and the encompassing air. ${ }^{155}$ Aluminum chlorohydrate and aluminum zirkonium tetrachlorohydrate glycine complex are the most as often as possible utilized dynamic fixings in business antitranspirants today. Aluminum chloride and propantheline bromide, the anticholinergic substance, are important choices albeit less normal. Dynamic elements of deodorants are for the most part perfuming or bactericidal/bacteriostatic substances, for example, triclosan. Likewise, there are substances which are intended to tie insulting scents (for example zinc ricinoleate) or to impact the skin surface $\mathrm{pH}$ (for example triethyl citrate). ${ }^{156} \mathrm{~A}$ cleanser not just gives the cleaning of the scalp skin and hair as its essential capacity, however likewise additionally serves to condition and improve hair and goes about as an aide in the management of different scalp disorders. To accomplish this, different fixings in the correct proportion are blended to give a cleanser which is appropriate for people having diverse hair types and hair need. Among the fixings that go into the creation of a cleanser are cleansers, conditioners, thickeners, sequestering operators, $\mathrm{pH}$ agents, additives and strength added substances. Hair conditioners are intended to improve hair reasonability; decline hair electricity produced via friction and includes brilliance. They are utilized in a few different ways relying on the condition of hair and requirement of the individual. ${ }^{157}$ During the 2000s, nail polish makers began advancing "3-Free" items, eliminating three broadly announced lethal synthetic concoctions: toluene, formaldehyde, and dibutyl phthalate (DnBP). Be that as it may, DnBP was in some cases supplanted by another endocrine-upsetting plasticizer, triphenyl phosphate (TPHP). Some new "n-Free" names have since showed up, with no institutionalization on which $\mathrm{n}$ synthetics are prohibited. This investigation expected to look at estimated plasticizer content against nail polish names. The restricted guideline of fixings in nail polish may leave nail polish clients and nail salon workers powerless. Consumers that utilization nail polish generally comprise of women, frequently of kid bearing age, and even youngsters. Statistical surveying proposes that consumers apply nail polish two to six times each month all things considered, or as much as once every day. ${ }^{12}$ Lipsticks may not just expand the difference among lips and facial skin however may likewise impact apparent delicacy of skin. Therefore, it would be both experimentally intriguing and helpful for down to earth purposes to test the impact of lip color on facial skin's apparent softness. Kobayashi et al. ${ }^{158,159}$ inspected that lip color was absorbed into facial skin's apparent color. For instance, they found that orange lip color influences facial skin to seem yellowish, and rosy lip color influences facial skin to seem ruddy and lighter. ${ }^{37}$ Worthy lipstick for the consumers should have an appropriate surface and spread ability. Clear sensory profiling is a fundamental device in this procedure as it enables an accomplished board to evaluate the subjective and quantitative attributes of an item. ${ }^{160}$

\section{Cosmetics vehicles}

Consumers will pay a premium for elite skin and hair care items. The interest exists, and as a byproduct of the surprising expense, consumers anticipate that the item should perform as guaranteed and to fulfill tasteful guidelines past numerous items found in the mass market. To be fruitful in this very aggressive market, items must capacity as guaranteed or consumers won't repurchase. Successful contemporary top of the line items must be appropriately formulated in nonirritating vehicles that consumers will see as exquisite. ${ }^{161}$ Cosmetic items mean any substance or blend planned to be set in contact with the outside pieces of the human body (e.g., epidermis, lips) and ought not go to the lower parts and infiltrate to the skin. ${ }^{162}$ In cosmetics, the expression "dynamic fixing" is an advertising term for a fixing that individuals accept has some impact yet isn't lawfully permitted to. For instance, a few advertisers state Vitamin $\mathrm{C}$ is a functioning element for skin helping. While there might be some lab concentrates to demonstrate this fixing may have an impact it's anything but an endorsed element for skin helping, so it's not by any stretch of the imagination a functioning fixing. Truth be told, in the event that it affected skin like that it would be a mislabeled medication. Fundamentally, there is no such thing as a functioning fixing in cosmetics. On the off chance that an item has a functioning fixing, it is a medication. Functional cosmetic fixings are those whose fundamental reason in the formula is to convey an advantage to a customer. They may have some optional impact of improving the vibe of the item when it's connected or balancing out the formula yet the essential reason, they are included is for the impact they have on skin or hair. ${ }^{163}$ Cosmetic surfactant performs detergency, wetting, emulsifying, solubilizing, scattering and frothing impacts. Antagonistic responses of substance union surfactant affect environment and people, especially serious in long haul. Biodegradability, low danger and environmental worthiness which are the advantages of normally determined surfactant that guarantees cosmetic wellbeing are, therefore, profoundly on interest. Biosurfactant producible from microorganisms displaying potential 
surface properties reasonable for cosmetic applications particularly incorporate with their organic exercises. Sophorolipids, rhamnolipids and mannosylerythritol lipids are the most broadly utilized glycolipids biosurfactant in cosmetics. To be sure, huge numbers of these biosurfactants could show a "prebiotic" character. ${ }^{164,165}$ Notwithstanding their surfactant limit, numerous biosurfactants can go about as great emulsifiers, which is an additional preferred standpoint in the arrangement of green cosmetic items. In this work, a biosurfactant acquired from Lactobacillus paracasei was utilized as a balancing out operator in oil-in-water emulsions containing basic oils and common cancer prevention agent remove. ${ }^{166}$ Surface-dynamic polysaccharides commonly must be utilized at generally abnormal states to deliver little beads, yet the beads formed are profoundly impervious to environmental changes. Then again, surface-dynamic proteins are commonly used at low dimensions, however the beads formed are exceedingly delicate to changes in $\mathrm{pH}$, ionic quality, and temperature. Certain phospholipids are equipped for delivering little oil beads amid homogenization, yet again the drops formed are very touchy to changes in environmental conditions. Biosurfactants (saponins) can be used at low dimensions to form fine oil beads that stay stable over a scope of environmental conditions. Some naturedetermined nanoparticles (e.g., cellulose, chitosan, and starch) are compelling at balancing out emulsions containing generally vast oil beads. Future research is urged to recognize, seclude, decontaminate, and portray new sorts of characteristic emulsifier, and to test their adequacy in sustenance, cosmetic, cleanser, individual consideration, and different items. ${ }^{167}$

\section{Cosmetics regulations}

The regulatory framework, consistence requirement, adequacy, security, and promoting of cosmetic items are viewed as the most important factors for development of the cosmetic business. The two most important laws relating to cosmetics promoted in the United States are the Federal Food, Drug, and Cosmetic Act (FD\&C Act) and the Fair Packaging and Labeling Act (FPLA). FDA controls cosmetics under the authority of these laws. In the United States, government laws are established by Congress. So as to make the laws work on an everyday dimension, Congress authorizes certain government offices. For example, FDA, to make guidelines. An adjustment in FDA's legitimate authority over cosmetics would expect Congress to change the law. ${ }^{168}$ There are distinctive regulatory bodies over the globe that have their very own bits of knowledge for guideline; moreover, governments, for example, the United States, European Union, and Japan pursue a stringent regulatory framework, while cosmetics are less carefully controlled in nations, for example, India, Brazil, and China. ${ }^{169}$ The alignment of a regulatory framework will assume a critical job in the evacuation of boundaries to exchange, development of market at a global dimension, advancement in the development and introduction of new items, and most importantly security and viability of the advertised items. Unfortunately, in spite of the efforts of European Authorities, the present enactment is as yet stratified and a few reactions remain due to the absence of entrenched logical information on nanomaterials. In spite of the fact that the regulatory framework for cosmetic items is practically finished, the viability and additionally wellbeing assessment of nanomaterials in therapeutic items and medicinal gadgets is as yet dependent on caseby-case assessment as a result of the multifaceted nature of such frameworks. ${ }^{170}$

The United States (U.S.) and European Union (EU) share a shared objective of guaranteeing the wellbeing of cosmetics for consumers through rigorous science-based guideline. The way by which each directs the security of cosmetics is very comparable. The present commitment gives knowledge into the important cosmetic guidelines in regions of premarket endorsement, fixing control, and naming and alerts, with an exceptional spotlight on the cosmetic regulatory environments in the United States, European Union, Japan, and India. The European Union's framework of compound and cosmetics guidelines is authoritative on all Member States Regulations and is enforced at the national dimension. Under the EU Commission, Regulation (EC) No. 1223/2009 is the key European enactment overseeing completed cosmetics items in the EU Each nation in the EU has a skillful authority that is in charge of maintaining consistence. ${ }^{169,171}$ In India, cosmetics are controlled according to Drugs and Cosmetics Act 1940 and Rules 1945. Part-XIII (directs import and enlistment of cosmetics), part-XIV (assembling of cosmetic for deal or for dissemination) and part-XV (manages marking, pressing and guidelines of cosmetics). ${ }^{172}$ In Japan, cosmetics are managed by the Ministry of Health, Labor, and Welfare (MHLW) under the Pharmaceutical Affairs Law (PAL). For lawful reasons, cosmetics are partitioned into semi medications and cosmetics. ${ }^{173}$ In Australia, the importation, assembling and utilization of synthetic concoctionsincorporating those utilized in cosmetics - is managed by the Australian Government's National Industrial Chemicals Notification and Assessment Scheme (NICNAS). NICNAS works to guarantee that synthetic compounds utilized in purchaser items don't make critical mischief clients or to the environment. ${ }^{174}$

\section{Epilogue}

Civilizations have utilized cosmetics-however not constantly conspicuous contrasted with the present propelled items-for hundreds of years in religious ceremonies, to upgrade beauty, and to advance great wellbeing. Cosmetics utilization since the beginning can be demonstrative of a development's down to earth concerns, for example, insurance from the sun, sign of class, or shows of beauty. Individuals use cosmetics to keep clean and upgrade their beauty. These items extend from lipstick and nail polish to deodorant, scent, hairspray, cleanser, shower gel, tattoos, hair glues, hair evacuation items, hair colors, most cleansers, some tooth whiteners, and some cleansing wipes. Physical appearance is a vital segment of self-introduction in every single social circumstance, including that of applying for work. Cosmetics contain countless, the vast majority of which are not under the regulatory domain of the Food and Drug Administration. Just a couple of these synthetic substances have been assessed for potential malicious wellbeing sway: parabens, phthalates, polycyclic fragrant hydrocarbons, and siloxanes. While the current logical reasoning on a significant number of these synthetic substances is that they are sheltered to utilize, it is dependent upon every purchaser to settle on their own choice regarding whether they buy and utilize an item containing certain fixings or not. Consumers ought to likewise endeavor to buy trustworthy brands from built up merchants - modest imports or duplicates purchased online might not have experienced the best possible testing and assessment process and may not contain what they guarantee to. ${ }^{175-182}$

\section{Article summary}

Cosmetology incorporates the most exceptional logical information and innovation including science, pharmacology, sub-atomic science, hereditary/new materials designing, immunology, and nervous system science, and so on. Cosmetics are promptly accessible today as creams, lipstick, scents, eye shadows, nail polishes, hair sprays and so on. Different cosmetics like face powder offer sparkle to the skin 
in the wake of applying the base cream. Cosmetic fixings/excipients are incorporated to acquire detergency, wetting, emulsifying, recoloring and mitigating impacts. Unfriendly responses of synthetics have impacts on environment and people, especially serious in long haul. Numerous cosmetics have restorative impacts being used. Once more, unique populace has distinctive profile of cosmetics use. As an outcome of this expanding use of science to beauty, the line among cosmetic and medicinal research is getting to be obscured; the laboratories of major cosmetic organizations perform bleeding edge explore in territories, for example, grid science, cell reinforcements and maturing forms. Appropriate principles and guideline ought to be forced on their assembling, advertising and conveyances alongside valuing.

\section{Acknowledgments}

It's a significant privilege and appreciation to be drug specialists in research and training process. All drug specialists, authorities, columnists, magazine experts and partners that I met in this intention, were caring and accommodating. I'm appreciative to Lauren Balukonis, account official inside the beauty division at $5 \mathrm{~W}$ Public Relations, working with the two business people and set up brands and Dr. Rashmi Taneja, Plastic and Cosmetic Surgeon in Vasant Kunj, Delhi for their valuable time to survey my article and given their attentive recommendations. I'm additionally thankful to original library of Faculty of Pharmacy, University of Dhaka and BANSDOC Library, Bangladesh for giving me books, diary and pamphlets. The best help was from understudies and associates who ceaselessly supported me in gathering and information extraction from books, diaries, pamphlets and valuable time in exchange pursued by giving information on patient consistence, sane medication use and remedial monitoring. A portion of this article is for some time been addressed as course material. Along these lines, it is particularly useful for me to convey better than anyone might have expected the same number of more things are considered.

\section{Compliance with the ethical issues}

\section{Ethics approval and consent to participate}

Animal and Human experiment: N/A

Human Data Submission Approval: N/A

\section{Consent for publication}

Consent to publish Individual Person's data: N/A

\section{Availability of data and materials}

Data sharing: Please contact author for data requests

\section{Competing interests}

The author declares that he has no competing interests

\section{Funding}

Funding from individual/Organization: N/A

\section{Authors' contributions}

The individual contributions of authors: N/A

\section{References}

1. Laliberte M. 10 Beauty Secrets to Steal from Marilyn Monroe. Web Reader's Digest.
2. Forster A. Marilyn Monroe's beauty secrets: The most surprising tips from Hollywood's ultimate icon. Fashion Magazine. 2016.

3. Marilyn Monroe Quotes Pinterest. Blog I'm Still a woman, October 27, 2012.

4. REVEALED: Asparagus Stem Cells Are The Answer To Hair Loss!

5. Trehan S, Michniak-Kohn B, Beri K. Plant stem cells in cosmetics: current trends and future directions. Future Sci OA. 2017;3(4):FSO226.

6. Musazzi UM, Marini V, Casiraghi A, et al. Is the European regulatory framework sufficient to assure the safety of citizens using health products containing nanomaterials? Drug Discov Today. 2017;22(6):870-882.

7. Chapter 2. The body with limits. In: The Future of Post-Human Performing Arts: A Preface to a New Theory of the Body and its Presence by Peter Baofu. Published by Cambridge Scholars Publishing. 2013, ISBN1443844853, 9781443844857.

8. Cosmetics. In: Cosmetic Chemistry: An Instant Approach by Ayaz Mahmood Dar. Educreation Publishing.

9. International Modeling Guide-5th Edition by Regina Niallah. FTC Publications, Inc. 2007.

10. Web L'Oréal Paris USA. Bronzer vs. Contour: What's the Difference?

11. Tolentino G. In What Order Do I Apply My Skin Care Products? Web DermStore.com (Skin Care Blogs).

12. Berdai MA, Labib S, Chetouani K, et al. Atropa belladonna intoxication: a case report. Pan Afr Med J. 2012;11:72.

13. Schultes RE, Hofmann A. Plants of the Gods: Origins of Hallucinogenic Use (pp 88). Paris: Hutchinson; 1980. ISBN 0091416000, 9780091416003.

14. Tombs S, Silverman I. Pupillometry: A sexual selection approach. Evolution and Human Behavior, 2004;25(4):221-228.

15. Web cosmeticsinfo.org. A History Of Cosmetics From Ancient Times

16. Jones O, Selinger B. The chemistry of cosmetics. Web Australian Academy of Science. 2018.

17. MAC-Makeup-Collection-Holiday-2013.

18. Balukonis L. Cosmetics A Look into the Past, Present and Future.

19. Donna Maria. Making Aromatherapy Creams \& Lotions: 101 Natural Formulas to Revitalize \& Nourish Your Skin. Massachusetts: Storey Publishing, LLC; 2018. ISBN 161212240X, 9781612122403.

20. Sandi Brenner. Beauty and the Budget. Published by Sandi Brenner; 2006. ISBN 1589399269, 9781589399266.

21. Stephen MS. Skin Sense! A Dermatologist's Guide to Skin and Facial Care; 3rd ed. Indiana: iUniverse; 2009. ISBN 1440174288, 9781440174285.

22. Nelson Lee Novick. Super Skin: A Leading Dermatologist's Guide to the Latest Breakthrough in Skin Care. Indiana: Universe; 2000 ISBN $1475922132,9781475922134$.

23. Irwin B, McPherson M. Your Best Face without Surgery: Looking Your Best without Plastic Surgery. California: Hay House Inc.; 2002. ASIN: B004C03L1E.

24. John T, Darrell K, Van Cleef-Toedt K. Chemical Composition of Everyday Products, ABC-Clio ebook Gale virtual reference library. Connecticut: Greenwood Publishing Group; 2005. ISBN 0313325790 , 9780313325793 .

25. Cosmetic tattoo Sydney specialist Lana Shine. Available From: http:// lanashine.com/\#!/pageLips

26. www.narscosmetics.com/USA/lips

27. Dionisio KL, Phillips K, Price PS, et al. The Chemical and Products Database, a resource for exposure-relevant data on chemicals in consumer products. Sci Data. 2018;5:180125. 
28. EWG's Skin Deep® Cosmetic Database.

29. Anna Savina. Permanent Lip Makeup. Anna Savina LLC. Dec 28, 2013.

30. Why the Mineral Primer is the Best Friend of Your Makeup?

31. Kobayashi Y, Matsushita S, Morikawa K. Effects of Lip Color on Perceived Lightness of Human Facial Skin. Iperception. 2017;11;8(4):2041669517717500.

32. Oliver D. What Is Makeup Primer, And Do You Need It? The Huffington Post, December 21, 2017.

33. How to Use Primer like a Pro - Superdrug. Available From: https://www superdrug.com > Home > Beauty Manuals > How to Use Primer Like a Pro.

34. Roberts WE, Jiang LI, Herndon JH Jr. Facial primer provides immediate and long-term improvements in mild-to-moderate facial hyperpigmentation and fine lines associated with photoaging. Clin Cosmet Investig Dermatol. 2015;8:471-477.

35. Denton-Hurst T. How to Pick the Best Makeup Primer for you and apply it Like a Pro. Web makeup.com Tutorial, September 7, 2018.

36. Seikali A. Disney Unveils Seven Dwarfs Mine Train Footage (VIDEO). Web Variety.com, February 24, 2014.

37. Rayner VL. Camouflage therapy. Dermatol Clin. 1995;13(2):467-472.

38. Monfrecola G, Cacciapuoti S, Capasso C, et al. Tolerability and camouflaging effect of corrective makeup for acne: results of a clinical study of a novel face compact cream. Clin Cosmet Investig Dermatol. 2016;9:307-313.

39. Levy LL, Emer JJ. Emotional benefit of cosmetic camouflage in the treatment of facial skin conditions: personal experience and review. Clin Cosmet Investig Dermatol. 2012;5:173-182.

40. Sarveswari KN. Cosmetic camouflage in vitiligo. Indian J Dermatol. 2010;55(3):211-214

41. Concealer for Skin Imperfections.

42. Draelos ZD. Active agents in common skin care products. Plast Reconstr Surg. 2010;125(2):719-724.

43. Moore A. The biochemistry of beauty. The science and pseudo-science of beautiful skin. EMBO Rep. 2002;3(8):714-717.

44. Tagai K, Shimakura H, Isobe H, et al. The light-makeup advantage in facial processing: Evidence from event-related potentials. PLoS One. 2017;12(2):e0172489.

45. Kilkeary AM. What Comes First-Foundation or Concealer? Here's What You Need to Know. Web makeup.com Tutorial, January 2, 2019.

46. Under Eye Concealer Setting Powder: Top Selected Products and Reviews.

47. ATKINS F. Analysis of face powder. Manuf Chem Aerosol News. 1948;19(12):565.

48. Everything you need to know about face powders.

49. Lubitz R. The gruesome and lengthy history of why we use blush.

50. These are the best blushes for making your dewy skin dreams come true (including a $£ 10$ steal). Glamour Magazine, Friday 8 March 2019.

51. Carole Jackson. Color Me Beautiful Makeup Book. New York: Ballantine Books; 1988. ISBN 0345348427, 9780345348425.

52. Ruth Drake. Redbook's complete guide to beauty, published by Grosset \& Dunlap, 1973 ISBN 044801291X, 9780448012919

53. Natural eye makeup for blue eyes. lakesidersrochester.com

54. Janet Simms. A Practical Guide to Beauty Therapy for NVQ Level 2. Cheltenham: Nelson Thornes; 2003. ISBN 0748771506, 9780748771509.
55. Bronzer vs. Contour: What's the Difference?

56. Sandra Morris. The beauty manual: how to look your best ever. Published by Lowell House: 1999, ISBN 0737305053, 9780737305050.

57. Should I Use Shimmer Bronzer, Matte Bronzer, or Sheer Bronzer?

58. Parry C, Eaton J. Kohl: a lead-hazardous eye makeup from the Third World to the First World. Environ Health Perspect. 1991;94:121-123.

59. Ng A, Evans K, North RV, et al. Impact of Eye Cosmetics on the Eye, Adnexa, and Ocular Surface. Eye Contact Lens. 2016;42(4):211-220.

60. Top Facial Treatment Stock Photos. istockphoto.com

61. https://rayorconcept.blogspot.com/2016/10/writeup-cosmeticsmakeup. html

62. Sinks T. Everything You Need to Know About Mascara. Web lifehacker. com, January 5, 2017.

63. Michelle Phan. Make Up: Your Life Guide to Beauty, Style, and Success-Online and Off, published by Potter/Ten Speed/Harmony/Rodale, 2014, ISBN 1101903074, 9781101903070

64. Sharon Parsons. The Chemistry of Cosmetics. Oceania: Cengage Learning Australia. 2013, ISBN $0170229513,9780170229517$.

65. http://www.gulabifashion.com/eye-makeup/

66. Marjorie Grimm. Permanent Cosmetics: The Foundation of Fundamental Applications. Independent Publisher: 2018. ISBN $1532368526,9781532368523$.

67. What is makeup setting spray and how does it help keep your makeup in place.

68. Face Wash vs. Cleanser vs. Scrub: What's the Difference?

69. Villette M. How to Choose the Best Cleanser for Your Skin? Villette M. Web theskincareedit.com February 3, 2016.

70. Charlotte Cho. The Little Book of Skin Care: Korean Beauty Secrets for Healthy, Glowing Skin. New York: Harper Collins; 2015. ISBN 0062416383,9780062416384 .

71. General Skincare programs.

72. Julie Gabriel. The Green Beauty Guide: Your Essential Resource to Organic and Natural Skin Care, Hair Care, Makeup, and Fragrances. Hyderabad: Health Communications. Inc., 2008 ISBN 0757307477, 9780757307478. 400p.

73. Tarun J, Susan J, Suria J, et al. Evaluation of $\mathrm{pH}$ of Bathing Soaps and Shampoos for Skin and Hair Care. Indian JDermatol. 2014;59(5):442-444.

74. Mukhopadhyay P. Cleansers and their role in various dermatological disorders. Indian J Dermatol. 2011;56(1):2-6.

75. Williams SD. Chemistry and Technology of the Cosmetics and Toiletries Industry. Williams DF, Schmitt WH, eds. Berlin: Springer Science \& Business Media. 1992.

76. D'Souza P, Rathi SK. Shampoo and Conditioners: What a Dermatologist Should Know? Indian J Dermatol. 2015;60(3):248-254.

77. Trüeb RM. Shampoos: ingredients, efficacy and adverse effects. J Dtsch Dermatol Ges. 2007;5(5):356-365.

78. Draelos ZD. Essentials of Hair Care often Neglected: Hair Cleansing. Int J Trichology. 2010;2(1):24-29.

79. Gavazzoni Dias MF. Hair cosmetics: an overview. Int $J$ Trichology. 2015;7(1):2-15.

80. Benohanian A. Antiperspirants and deodorants. Clin Dermatol. 2001;19(4):398-405.

81. Zirwas MJ, Moennich J. Antiperspirant and deodorant allergy: diagnosis and management. J Clin Aesthet Dermatol. 2008;1(3):38-43. 
82. Burry JS, Evans RL, Rawlings AV, et al. Effect of antiperspirants on whole body sweat rate and thermoregulation. Int $J$ Cosmet Sci. 2003;25(4):189-192.

83. Callewaert C, Hutapea P, Van de Wiele T, Boon N. Deodorants and antiperspirants affect the axillary bacterial community. Arch Dermatol Res. 2014;306(8):701-710.

84. Lodén M, Wessman C. The antidandruff efficacy of a shampoo containing piroctone olamine and salicylic acid in comparison to that of a zinc pyrithione shampoo. Int J Cosmet Sci. 2000;22(4):285-289.

85. Schwartz JR, Bacon RA, Shah R, et al. Therapeutic efficacy of antidandruff shampoos: a randomized clinical trial comparing products based on potentiated zinc pyrithione and zinc pyrithione/climbazole. Int $J$ Cosmet Sci. 2013;35(4):381-387.

86. Victor R Preedy. Handbook of Hair in Health and Disease. Human health handbooks. Berlin: Springer Science \& Business Media. 2012; 493 p.

87. Cury JA, Tenuta LM. Evidence-based recommendation on toothpaste use. Braz Oral Res. 2014; 28 Spec No:1-7.

88. Lippert F. An introduction to toothpaste - its purpose, history and ingredients. Monogr Oral Sci. 2013;23:1-14.

89. C van Loveren. Toothpastes Volume 23 of Monographs in oral science. Basel: Karger Medical and Scientific Publishers. 2013.

90. Davies RM, Ellwood RP, Davies GM. The rational use of fluoride toothpaste. Int J Dent Hyg. 2003;1(1):3-8.

91. Jahangir GZ, Ashraf DS, Nasir IA, et al. The myth of oral hygiene using synthetic mouthwash products. Springerplus. 2016;2;5(1):1481.

92. Ciancio SG. Mouthwashes: Rationale for use. Am J Dent. 2015;28 Spec No A:4A-8A.

93. Alshehri FA. The use of mouthwash containing essential oils (LISTERINE®) to improve oral health: A systematic review. Saudi Dent J. 2018;30(1):2-6.

94. Pereira EM, da Silva JL, Silva FF, et al. Clinical Evidence of the Efficacy of a Mouthwash Containing Propolis for the Control of Plaque and Gingivitis: A Phase II Study. Evid Based Complement Alternat Med. 2011;2011:750249.

95. Bajpai D, Tyagi VK. Laundry detergents: an overview. J Oleo Sci. 2007;56(7):327-40.

96. Habib RR, El-Masri A, Heath RL. Women's strategies for handling household detergents. Environ Res. 2006;101(2):184-194.

97. Liu X, Lao XQ, Wong CC, et al. Frequent use of household cleaning products is associated with rhinitis in Chinese children. J Allergy Clin Immunol. 2016;138(3):754-760.e6

98. Hong S, Kwon HJ, Choi WJ, et al. Association between exposure to antimicrobial household products and allergic symptoms. Environ Health Toxicol. 2014;29:e2014017.

99. Sherriff A, Farrow A, Golding J, et al. Frequent use of chemical household products is associated with persistent wheezing in pre-school age children. Thorax. 2005;60(1):45-49.

100. Coret CD, Suero MB, Tierney NK. Tolerance of natural baby skin-care products on healthy, full-term infants and toddlers. Clin Cosmet Investig Dermatol. 2014;7:51-58

101. Sathyanarayana S, Karr CJ, Lozano P, et al. Baby care products: possible sources of infant phthalate exposure. Pediatrics. 2008;121(2):e260-e268.

102. Kuller JM. Infant Skin Care Products: What Are the Issues? Adv Neonatal Care. 2016;16 Suppl 5S:S3-S12.

103. Gao X, Simpson EL. Market trends in baby skin care products and implications for clinical practice. Pediatr Dermatol. 2014;31(6):734-738.
104. Cooke A, Bedwell C, Campbell M, et al. Skin care for healthy babies at term: A systematic review of the evidence. Midwifery. 2018;56:29-43.

105. The Choice Guide to Baby Product: The Buying Guide for Parents.

106. Eichenfield L, Frieden I, Mathes E, et al. Neonatal Dermatology E-Book 2nd ed. Amsterdam: Elsevier Health Sciences; 2007.

107. Dennis Laba. Rheological Properties of Cosmetics and Toiletries Cosmetic Science and Technology. Laba D, Dekker M, editors. New York: CRC Press. 1993. 440 p.

108. Groot AC, Nater JP, Lender R, et al. Adverse effects of cosmetics and toiletries: a retrospective study in the general population. Int $J$ Cosmet Sci. 1987;9(6):255-259.

109. Sportiello L, Cammarota S, de Portu S, et al. Notification of undesirable effects of cosmetics and toiletries. Pharmacol Res. 2009;59(2):101-106.

110. http://www.esterform.com/market-sectors/household-toiletries-andpersonal-care/

111. Poonyakan A, Rachakornkij M, Wecharatana M, et al. Potential Use of Plastic Wastes for Low Thermal Conductivity Concrete. Materials (Basel). 2018;11(10). pii: E1938.

112. Weatherly LM, Gosse JA. Triclosan exposure, transformation, and human health effects. J Toxicol Environ Health B Crit Rev. 2017;20(8):447-469.

113. McNary JE, Jackson EM. Inhalation exposure to formaldehyde and toluene in the same occupational and consumer setting. Inhal Toxicol. 2007;19(6-7):573-576.

114. Kim S, Lee S, Shin C, et al. Urinary parabens and triclosan concentrations and associated exposure characteristics in a Korean population-A comparison between night-time and first-morning urine. Int $\mathrm{J} \mathrm{Hyg}$ Environ Health. 2018;221(4):632-641.

115. Nowak K, Ratajczak-Wrona W, Górska M, et al. Parabens and their effects on the endocrine system. Mol Cell Endocrinol. 2018;474:238-251.

116. Koniecki D, Wang R, Moody RP, et al. Phthalates in cosmetic and personal care products: concentrations and possible dermal exposure. Environ Res. 2011;111(3):329-336.

117. Kim YM, Kim J, Cheong HK, et al. Exposure to phthalates aggravates pulmonary function and airway inflammation in asthmatic children. PLoS One. 2018;13(12):e0208553.

118. Johansen JD, Rastogi SC, Andersen KE, et al. Content and reactivity to product perfumes in fragrance mix positive and negative eczema patients. A study of perfumes used in toiletries and skin-care products. Contact Dermatitis. 1997;36(6):291-296.

119. Zhou J, Tierney NK, McCarthy TJ, et al. Estimating infants' and toddlers inhalation exposure to fragrance ingredients in baby personal care products. Int J Occup Environ Health. 2017;23(4):291-298.

120. Barrett JR. The ugly side of beauty products. Environ Health Perspect. 2005;113(1):A24.

121. Crinnion WJ. Toxic effects of the easily avoidable phthalates and parabens. Altern Med Rev. 2010;15(3):190-196.

122. Darbre PD. Underarm antiperspirants/deodorants and breast cancer Breast Cancer Res. 2009;11 Suppl 3:S5.

123. Bronaugh RL, Congdon ER, Scheuplein RJ. The effect of cosmetic vehicles on the penetration of $\mathrm{N}$-nitrosodiethanolamine through excised human skin. J Invest Dermatol. 1981;76(2):94-96.

124. Bergfeld WF, Belsito DV, Marks JG Jr, et al. Safety of ingredients used in cosmetics. J Am Acad Dermatol. 2005;52(1):125-132.

125. Ross G. A perspective on the safety of cosmetic products: a position paper of the American Council on Science and Health. Int $J$ Toxicol. 2006;25(4):269-277. 
126. Larsson K, Ljung Björklund K, Palm B, et al. Exposure determinants of phthalates, parabens, bisphenol A and triclosan in Swedish mothers and their children. Environ Int. 2014;73:323-33.

127. Halla N, Fernandes IP, Heleno SA, et al. Cosmetics Preservation: A Review on Present Strategies. Molecules. 2018;23(7). pii: E1571.

128. Cornell EM, Janetos TM, Xu S. Time for a makeover-cosmetics regulation in the United States. J Cosmet Dermatol. 2019.

129. Hsu T. Johnson \& Johnson Told to Pay $\$ 4.7$ Billion in Baby Powder Lawsuit (Business Article). The New York Times July 12, 2018.

130. Bellon T. Jury orders J\&J to pay $\$ 4.7$ billion in Missouri asbestos cancer case ((Business Article). Reuters. 2018

131. Narayan P. The cosmetics industry has avoided strict regulation for over a century. Now rising health concerns has FDA inquiring. CNBC News. 2018.

132. Edgar J. WEN Case Spurs Call for Beauty Product Regs. WebMD Health News. 2018.

133. McMillen M. Banned From Soap, Is Triclosan Still a Concern? Medscape. 2018.

134. Louis CS. Why a Chemical Banned From Soap Is Still in Your Toothpaste? The New York Times. 2016

135. Helmenstine AM. Toxic Chemicals in Cosmetics. Web ThoughtCo. 2019

136. Lee HJ, Jeong SE, Lee S, et al. Effects of cosmetics on the skin microbiome of facial cheeks with different hydration levels. Microbiologyopen. 2018;7(2):e00557.

137. Vogel L. US legislators propose crackdown on toxic cosmetics. CMAJ. 2011;183(16):E1169-E1170.

138. Inamadar AC, Palit A. Sensitive skin: an overview. Indian J Dermatol Venereol Leprol. 2013;79(1):9-16.

139. Minamoto K. [Skin sensitizers in cosmetics and skin care products]. Nihon Eiseigaku Zasshi. 2010;65(1):20-29.

140. Katz U, Shoenfeld Y, Zakin V, et al. Scientific evidence of the therapeutic effects of Dead Sea treatments: a systematic review. Semin Arthritis Rheum. 2012;42(2):186-200.

141. Handbook of Cosmetic Science and Technology. 4th ed. In: André OB, Paye M, Howard IM. Florida: CRC Press. 2014; ISBN 1842145649 , 9781842145647.

142. Kanlayavattanakul M, Lourith N. Plants and Natural Products for the Treatment of Skin Hyperpigmentation - A Review. Planta Med. 2018;84(14):988-1006.

143. Baumann L, Woolery-Lloyd H, Friedman A. "Natural" ingredients in cosmetic dermatology. J Drugs Dermatol. 2009;8(6 Supp 1):s5-s9.

144. Coret CD, Suero MB, Tierney NK. Tolerance of natural baby skin-care products on healthy, full-term infants and toddlers. Clin Cosmet Investig Dermatol. 2014;7:51-58.

145. Pérez-Sánchez A, Barrajón-Catalán E, Herranz-López $\mathrm{M}$, et al. Nutraceuticals for Skin Care: A Comprehensive Review of Human Clinical Studies. Nutrients. 2018;10(4). pii: E403.

146. Eric S Abrutyn. Chapter 1. Building Natural Products. In: Primer on Formulating NATURAL Products. 2012.

147. Bojanowski K. Hypodermal delivery of cosmetic actives for improved facial skin morphology and functionality. Int $J$ Cosmet Sci. 2013;35(6):562-567.

148. Smit N, Vicanova J, Pavel S. The hunt for natural skin whitening agents. Int J Mol Sci. 2009;10(12):5326-5349.

149. Pillaiyar T, Manickam M, Namasivayam V. Skin whitening agents: medicinal chemistry perspective of tyrosinase inhibitors. $J$ Enzyme Inhib Med Chem. 2017;32(1):403-425.

150. Desmedt B, Courselle P, De Beer JO, et al. Overview of skin whitening agents with an insight into the illegal cosmetic market in Europe. $J$ Eur Acad Dermatol Venereol. 2016;30(6):943-950.

151. Hollinger JC, Angra K, Halder RM. Are Natural Ingredients Effective in the Management of Hyperpigmentation? A Systematic Review. J Clin Aesthet Dermatol. 2018;11(2):28-37.

152. Dupont E, Journet M, Oula ML, et al. An integral topical gel for cellulite reduction: results from a double-blind, randomized, placebo-controlled evaluation of efficacy. Clin Cosmet Investig Dermatol. 2014;7:73-88.

153. Steiling W, Buttgereit P, Hall B, et al. Skin exposure to deodorants/antiperspirants in aerosol form. Food Chem Toxicol. 2012;50(6):2206-2215.

154. Lukacs VA, Korting HC. [Antiperspirants and deodorants--ingredients and evaluation]. Derm Beruf Umwelt. 1989;37(2):53-57.

155. Young AS, Allen JG, Kim UJ, et al. Phthalate and Organophosphate Plasticizers in Nail Polish: Evaluation of Labels and Ingredients. Environ Sci Technol. 2018;52(21):12841-12850.

156. Kobayashi Y, Matsushita S, Morikawa K. Effects of Lip Color on Perceived Lightness of Human Facial Skin. Iperception. 2017;8(4):2041669517717500.

157. Julie Gabriel. The Green Beauty Guide: Your Essential Resource to Organic and Natural Skin Care, Hair Care, Makeup, and Fragrances. Hyderabad: Health Communications. Inc., 2008 ISBN 0757307477, 9780757307478. 400p.

158. Kasparaviciene G, Savickas A, Kalveniene Z, et al. Evaluation of Beeswax Influence on Physical Properties of Lipstick Using Instrumental and Sensory Methods. Evid Based Complement Alternat Med. 2016;3816460.

159. Epstein H. Cosmeceutical and polyphenols.. Clin Dermatol. 2009;27(5):475-478.

160. Pavlačková J, Egner P, Polašková J, et al. Transdermal absorption of active substances from cosmetic vehicles. J Cosmet Dermatol. 2019.

161. Romanowski P. What is an active ingredient in cosmetics?

162. Lourith N, Kanlayavattanakul M. Natural surfactants used in cosmetics: glycolipids. Int J Cosmet Sci. 2009;31(4):255-261.

163. Vecino X, Cruz JM, Moldes AB, et al. Biosurfactants in cosmetic formulations: trends and challenges. Crit Rev Biotechnol. 2017;37(7):911-923.

164. Ferreira A, Vecino X, Ferreira D, et al. Novel cosmetic formulations containing a biosurfactant from Lactobacillus paracasei. Colloids Surf B Biointerfaces. 2017;155:522-529.

165. McClements DJ, Gumus CE. Natural emulsifiers - Biosurfactants, phospholipids, biopolymers, and colloidal particles: Molecular and physicochemical basis of functional performance. Adv Colloid Interface Sci. 2016;234:3-26.

166. Suhag J, Dureja H. Cosmetic Regulations: A Comparative Study. Skinmed. 2015;13(3):191-194.

167. Web US FDA. FDA Authority Over Cosmetics: How Cosmetics Are Not FDA-Approved, but Are FDA-Regulated.

168. Web cosmeticinfo.org. U.S. and EU Cosmetics Regulation.

169. Sarma P, Kumar H, Medhi B. Cosmetovigilance in India: Need of the day. Indian J Pharmacol. 2017;49(5):341-343.

170. Pharmacopeia TJ. The Japanese Pharmacopeia. 64 ${ }^{\text {th }}$ edition. Japan Ministry of Health. 2016;2486-2489.

171. Stan Place, Bobbi Ray Madry. The Art and Science of Professional 
Makeup Skin Series, published by Cengage Learning, 1989, ISBN 0873503619,9780873503617

172. Shahnaz Husain. Shahnaz Husain's Beauty Book. Hyderabad: Orient Paperbacks. 1998; ISBN: 8122200605, 9788122200607.

173. Krieger L. 10 Important Things You Need to Know Before Exfoliating Your Face. cosmopolitan.com.

174. Mark Lees. Skin Care: Beyond the Basics, published by Cengage Learning. 4th ed. 2013; ISBN 1133708390, 9781133708391.

175. Steinemann A. Fragranced consumer products: exposures and effects from emissions. Air Qual Atmos Health. 2016;9(8):861-866.

176. Patrick M. Skin Creams, Web skincare.lovetoknow.com
177. Nilforoushzadeh MA, Amirkhani MA, Zarrintaj P, et al. Skin care and rejuvenation by cosmeceutical facial mask. $J$ Cosmet Dermatol. 2018;17(5):693-702.

178. O'Reilly Beringhs A, Rosa JM, Stulzer HK, et al. Green clay and aloe vera peel-off facial masks: response surface methodology applied to the formulation design. AAPS PharmSciTech. 2013;14(1):445-455.

179. Abu-Jdayil B, Mohameed HA. A facial mask comprising Dead Sea mud. J Cosmet Sci. 2006;57(6):441-454.

180. Stephen ID, McKeegan AM. Lip colour affects perceived sex typicality and attractiveness of human faces. Perception. 2010;39(8):1104-1110.

181.https://faviana.com/blog/contour-your-face 